\title{
Aerosol Delivery Devices for Obstructive Lung Diseases
}

\author{
Roy A Pleasants PharmD BCPS and Dean R Hess PhD RRT FAARC
}

\author{
Introduction \\ History of Modern Aerosol Devices \\ Definition of Terms \\ Methods to Measure Aerosol Delivery and Deposition \\ Aerosol Deposition in the Airways \\ Inhaler Devices \\ Pressurized Metered-Dose Inhalers \\ Soft Mist Inhaler \\ Spacers and Holding Chambers \\ Dry Powder Inhalers \\ Smart Inhalers \\ Nebulizers \\ Jet Nebulizers \\ Face Mask Versus Mouthpiece \\ Designs to Decrease Aerosol Waste During Exhalation \\ Mesh Nebulizers \\ Ultrasonic Nebulizers \\ Smart Nebulizers \\ Continuous Aerosol Delivery \\ Use of Heliox With Nebulizers \\ Nebulizer/Formulation Combinations \\ Nebulizer Applications in Critical Care \\ Cleaning and Disinfection of Nebulizers \\ Clinical Studies Supporting the Impact of Aerosols \\ Inhalation Device Selection \\ Patient Education \\ Proper Inhalation Techniques \\ Summary
}

Drug delivery by inhalation is the principal strategy to treat obstructive lung diseases, which affect about $15 \%$ of the population in the United States. Aerosol delivery devices have evolved over more than 60 years from the basic pressurized metered-dose inhaler and nebulizer to numerous types of inhalers and devices, including valved holder chambers, dry powder inhalers, soft mist inhalers, as well as smart inhalers and nebulizers. Although these devices improve a patient's ability to self-administer medication, many problems with optimal delivery still exist. Appropriate selection and repeated patient education can help lessen the problems with these devices. Aerosol science is evolving, with methods of measurement that include radio-scintigraphy and magnetic resonance imaging, to provide a better understanding of aerosol delivery and effects. Understanding the science and clinical application of aerosol drug delivery can substantially aid clinicians in optimizing these therapies for their patients. Key words: inhalational therapies; COPD; asthma; dry powder inhalers; metered-dose inhalers; nebulization; patient education; smart inhalers; lung deposition. [Respir Care 2018;63(6):708-733. (C) 2018 Daedalus Enterprises] 


\section{Aerosol Delivery Devices for Obstructive Lung Diseases}

\section{Introduction}

Inhaled drug delivery is an integral component in the treatment of patients with asthma and COPD. A wide selection of inhaler devices is available, each with specific design characteristics. Therefore, choosing the most appropriate device to meet an individual patient's needs is an important clinical consideration. There are 3 major benefits of delivering medication via the inhaled route: rapid onset of action, high local concentration by delivery directly to the airways (and hence high therapeutic ratio and increased selectivity), and needle-free systemic delivery of drugs with poor oral bioavailability.

In the out-patient setting, inhalation is second only to the oral route for drug administration. Based on the prevalence of obstructive lung diseases in the United States, it is likely that $>25$ million people use inhaled medications. In 2014, inhaled medications sales exceeded $\$ 36$ billion in the United States. ${ }^{1}$ Unlike affected organs for most other major chronic diseases, direct delivery to the lungs is readily achievable. However, inhalation is one of the most complicated drug therapies for patients to self-administer, and it is more complex than appreciated by many patients and health care providers. The intent of this paper is to provide a broad perspective concerning the science and practice of aerosol drug therapies.

\section{History of Modern Aerosol Devices}

Commercial availability of modern day inhalers began in the 1950s with the pressurized metered-dose inhaler (pMDI). ${ }^{1}$ Although available since the 1970s, development of the dry powder inhaler was expanded by the 1987 Montreal Protocol eliminating chlorofluorocarbons (CFCs)

\footnotetext{
Dr Pleasants is affiliated with Duke Clinical Research Institute and Durham Veterans Administration Pulmonary Division, Durham, North Carolina. Dr Hess is affiliated with Massachusetts General Hospital, Harvard Medical School, and Northeastern University in Boston, Massachusetts. $\mathrm{He}$ is also Managing Editor of RESPIRATORY CARE.
}

Dr Pleasants discloses relationships with Astra Zeneca, Boehringer Ingelheim, GlaxoSmithKline, Sunovion, and Teva. Dr Hess discloses relationships with Philips Respironics, Ventec Life Systems, McGraw-Hill, Jones and Bartlett, UpToDate, Daedalus Enterprises, and the American Board of Internal Medicine.

Dr Pleasants presented a version of this paper at the 56th RESPIRATORY CARE Journal Conference, Respiratory Medications for COPD and Adult Asthma: Pharmacologic Actions to Clinical Applications, held June 22-23, 2017, in St Petersburg, Florida.

Correspondence: Dean R Hess PhD RRT FAARC, Respiratory Care, Massachusetts General Hospital, Boston, MA 02114. E-mail: dhess@mgh.harvard.edu.

DOI: $10.4187 /$ respcare.06290 in pMDIs. In the late 1970s, spacers and valved holding chambers were developed for patients with poor coordination and to decrease oropharyngeal deposition by slowing aerosol velocity and decreasing the number of large particles. Nebulizers have been available for centuries, but they can be less convenient, more time-consuming, more expensive, and thus have a secondary role in the outpatient setting. In the early 21 st century, the soft mist inhaler became available. Sanchis et $\mathrm{al}^{2}$ evaluated improper inhaler techniques and reported that many problems with the proper use of these devices still exist.

\section{Definition of Terms}

Deposition is a function of particle size, shape, and density, as well as anatomy of the lungs and breathing parameters (eg, flow and inhaled volume). ${ }^{3}$ The labeled dose (nominal dose) is the mass of drug that is available within the aerosol generator per actuation or inhalation; for example, for the albuterol pMDI, the labeled dose is $90 \mu \mathrm{g}$ per puff. The total emitted dose or delivered dose is the mass of drug emitted per actuation that is available for inhalation at the mouth, which is lower than the labeled dose. The fine-particle dose is the mass of particles $<5 \mu \mathrm{m}$ within the emitted dose. Fine-particle fraction is the fineparticle dose divided by the emitted dose. Mass median aerodynamic diameter (MMAD) is the diameter at which $50 \%$ of the particles of an aerosol by mass are larger and $50 \%$ are smaller. The optimal MMAD for obstructive lung disease is $1-5 \mu \mathrm{m}$; this is also referred to as the respirable particle range (or fraction). The geometric standard deviation (GSD) measures the dispersion of particle diameter. GSD is the ratio of the MMAD to the diameter at $15.9 \%$ of the probability scale, or the ratio of the diameter at $84.1 \%$ on the probability scale to the MMAD. Aerosols with a GSD $>1.15$ are considered polydisperse. A perfectly monodisperse aerosol (ie, one in which all aerosol particles have exactly the same size) has a GSD $=1$. Most therapeutic aerosols are polydisperse and have a GSD in the range of $2-3$. There are rationales for both monodiperse and polydisperse aerosols relative to delivery throughout the airways.

\section{Methods to Measure Aerosol Delivery and Deposition}

There are a number of methods to measure aerosol characteristics and delivery in the human lungs. ${ }^{4,5}$ Cascade impactors are often used to estimate MMAD and fineparticle dose of aerosol formulations. However, such in vitro measurements are limited in their ability to fully mimic the upper and lower respiratory tract and breathing pattern. Regulators require in vitro measurements, and in some cases in vivo measurements such as drug blood levels, to determine bioavailability of a new inhalational product. 

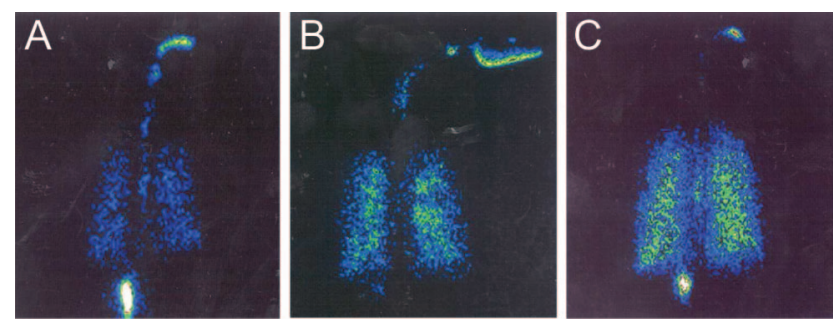

Fig. 1. Aerosol deposition with a pressurized metered-dose inhaler without a spacer (A), and with a spacer (B), compared to the soft mist inhaler $(\mathrm{C})$ using radio scintigraphy. From Reference 7 , with permission.

In vivo methodologies that image drug particles in humans include gamma scintigraphy, computed tomography, magnetic resonance imaging (MRI), and fluorescence imaging. In vivo methods that use isotopes are limited by high cost, high radiation doses, safety hazards, and training required for handling of radiolabeled isotopes., ${ }^{4,5}$ Gamma scintigraphy labels formulations with gamma ray-emitting radioisotopes and thus measures particle deposition and mucociliary clearance. There are limitations in the ability to label some inhalational products. Radio-scintigraphy uses radionuclides as an in vivo imaging technique to measure oropharyngeal and total lung deposition of particles. Figure 1 shows the use of radio-scintigraphy to evaluate aerosol deposition with different methods of delivery. ${ }^{6} \mathrm{MRI}$ and fluorescent imaging are considered the safest. In addition to measurement of ventilation, MRI with gas provides measurements of parenchyma microstructures, including the alveoli and acini. ${ }^{7}$ A study using MRI in subjects with COPD reported that spirometry was unable to detect changes in flow in the small airways, whereas MRI could. ${ }^{8}$ MRI will likely provide a much better understanding of the pharmacology of inhaled medicines, but it is in the early stages of application. In vivo imaging techniques are preferred over in vitro techniques because these can provide an image of regional deposition in the lungs.

Pharmacokinetic studies are also used to assess pulmonary deposition and systemic delivery of inhaled medications. The inhaled dose that reaches the lungs eventually diffuses into the systemic circulation, excluding the small portion of the inhaled drug that is exhaled or expectorated..$^{9} 10$ Although blood levels of inhaled drug do not necessarily correlate with therapeutic effects in the lungs, they do reflect lung deposition and potential for systemic effects, and they can be used to compare lung deposition between 2 inhaled formulations. Combined with the formulation's aerosol particle size and respirable fraction, pharmacokinetic data provides a more complete understanding of inhaled medication disposition. Manufacturers report pharmacokinetic data in the package insert. Aerosol particle size (MMAD) and fine-particle measures are typically reported in the literature and may be available from the manufacturer.

\section{Aerosol Deposition in the Airways}

Inhaled medications pass through the conducting and respiratory zones. ${ }^{4}$ The large airways, medium airways, and small airways (generations from 8 to 23 with $<2 \mathrm{~mm}$ internal diameter) are affected in asthma and COPD. Therefore, aerosol delivery throughout the airways is desirable. ${ }^{11}$ Muscarinic receptors are mostly in the medium and large airways, although muscarinic antagonist effects also occur in the small airways. The $\beta$ adrenoreceptors and corticosteroid receptors are distributed throughout the airways. ${ }^{3}$ Airway smooth muscle, which is affected by inhaled bronchodilators, is distributed in the non-cartilaginous portion of the airways, is denser in medium and larger airways, and is least dense in the terminal and respiratory bronchioles.

Size is an important determinant of particle deposition in the lungs (Fig. 2). There are 3 processes that affect aerosol deposition: inertial impaction, sedimentation, and diffusion. ${ }^{3,12}$ Larger particles tend to deposit by impaction in the oropharynx and larger conducting airways, whereas the smallest particles tend to deposit in the smaller conducting airways and in the distal airways, including the alveoli and terminal bronchioles. ${ }^{3,13,14}$ Each deposition process occurs rapidly, allowing the drug to exert its effects within minutes and before entering the systemic circulation. The tremors and relief of shortness of breath that occur within moments after albuterol inhalation are a reflection of how quickly the receptors in the lung respond and how rapidly a drug can reach the bloodstream and tissue receptors (skeletal muscle). The lung is the major route by which inhaled drugs reach the systemic circulation, as most agents have relatively poor systemic bioavailability through the gastrointestinal tract (eg, for beclomethasone, $\sim 20 \%$ of swallowed drug reaches the systemic circulation).

The high relative humidity of the airway affects particle deposition due to hygroscopic growth, contributing to deposition of drug on the respiratory epithelium. ${ }^{14}$ Impaction and sedimentation of aerosols are the dominant mechanisms of deposition of most inhaled medications. . $^{3,14}$ Inertial impaction occurs more in the oropharynx and upper airways, particularly at airway bifurcations and areas of obstruction. Depending on the characteristics of the drug, device, and patient, some portion of the drug is swallowed and absorbed into the systemic circulation from the gastrointestinal tract and/or is excreted through the gastrointestinal tract. Sedimentation of aerosolized particles depends on gravity, residence time in airway (eg, breath-hold time), airway dimensions, and patient position.

The inhaled drugs most likely to reach the airways, and thus exert local clinical effects, are aerosol particles in the fine-particle fraction of 1-5 $\mu \mathrm{m}$. The fine-particle fraction varies widely among inhalers, with $12-35 \%$ for DPI, $10-50 \%$ for pMDI, and $30-50 \%$ for the soft mist inhaler 


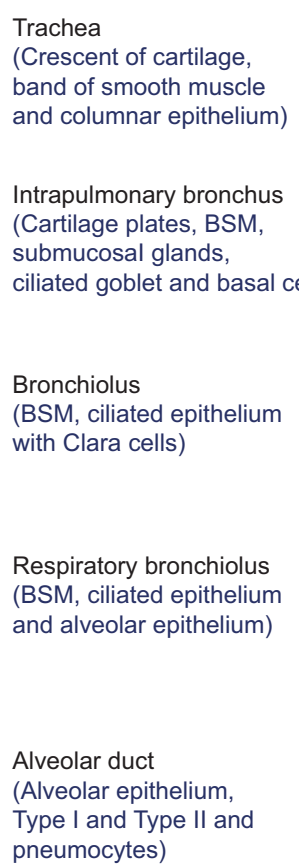

Respiratory bronchiolus (BSM, ciliated epithelium and alveolar epithelium)

Alveolar duct (Alveolar epithelium, Type I and Type II and pneumocytes)
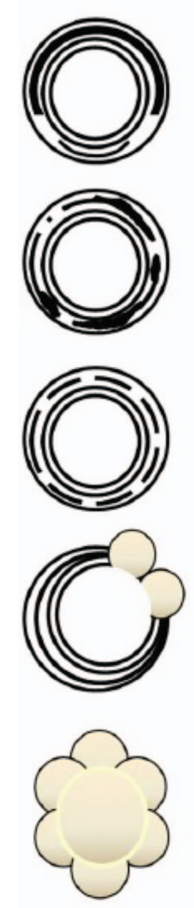

deposited)

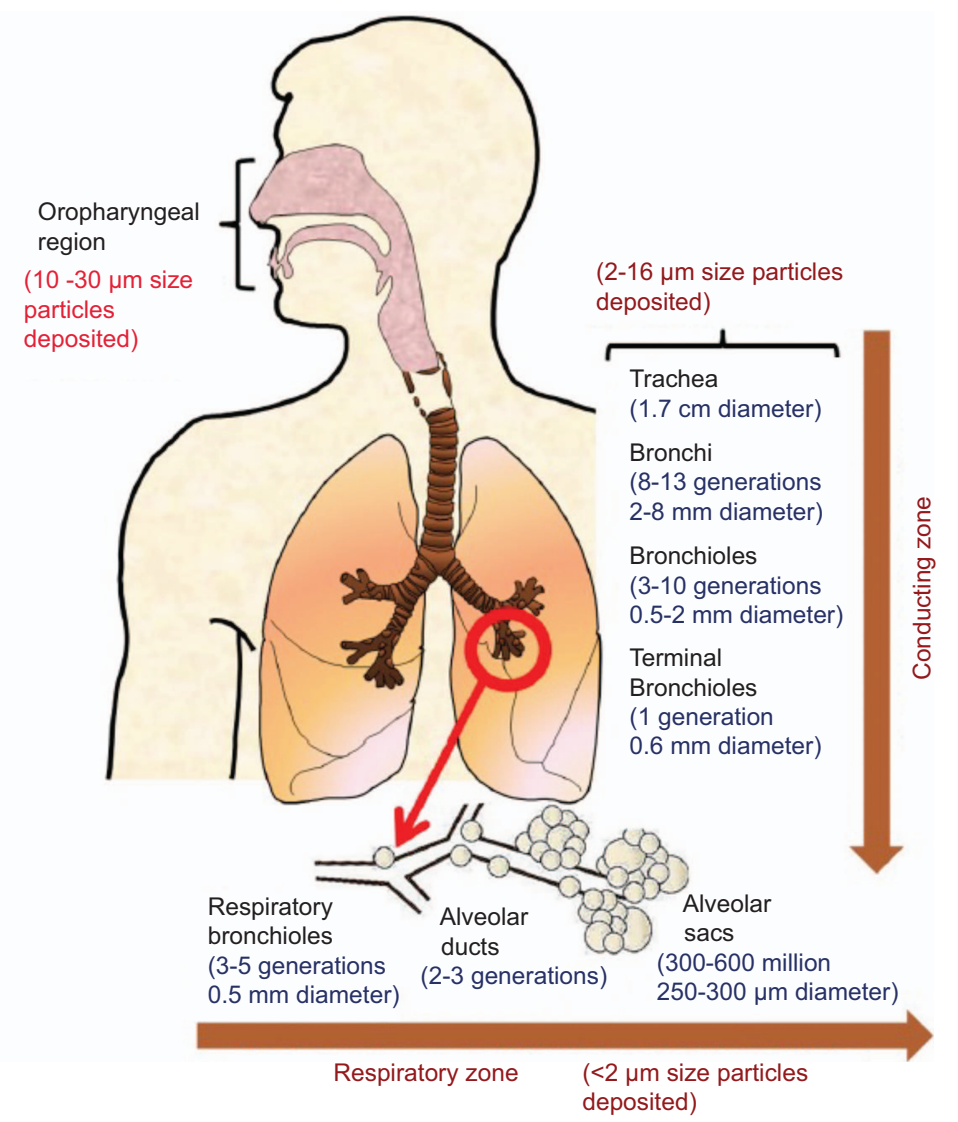
deposited)

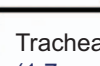

(1.7 cm diameter)

Bronchi $-8 \mathrm{~mm}$ diameter)

eposited)

Fig. 2. The adult lung with dimensions and generations of the airways with predicted aerosol deposition. BSM = bronchial smooth muscle. From Reference 4, with permission.

(SMI). Deposition of particles 3-7 $\mu \mathrm{m}$ in diameter occurs largely in the conducting airways, whereas particles $<2-3 \mu \mathrm{m}$ in diameter can reach the alveoli, particularly those $<1 \mu \mathrm{m}$ (see Fig. 2). 3,13,14 Particles $<0.5-1 \mu \mathrm{m}$ undergo Brownian motion, settle very slowly, and may be exhaled like a gas or may diffuse into the pulmonary capillaries after impaction. Diffusion of inhaled medications may be altered in smokers, where the tight junctions of the epithelium are damaged, allowing for more transport across the membranes. ${ }^{15}$ Air-flow obstruction and restriction can also determine in which parts of the lungs aerosol particles are deposited. There has been interest in the potential clinical benefits of delivering drug to the small airways. ${ }^{10,11}$

Clearance of drugs from the lungs is influenced by pharmacokinetic properties, including half-life, and physicochemical properties, such as molecular weight, lipophilicity, solubility, protein binding, and charge. ${ }^{14}$ Lipophilic molecules cross the airway epithelium by passive transport and hydrophilic molecules via extracellular pathways. Inhaled medications are often intentionally lipophilic to promote slow clearance from the lungs and thus exert a long duration of effect. Drug particles with a low dissolution rate that reach the alveolar space can be phagocytized by alveolar macrophages or absorbed into the pulmonary circulation. ${ }^{14}$
Particles deposited in the airways that are not absorbed are cleared by mucociliary transport and cough. Some inhaled medications can undergo metabolism in the lungs, such as the inhaled corticosteroid (ICS) beclomethasone dipropionate, whose metabolites diffuse into the bloodstream. ${ }^{16}$

\section{Inhaler Devices}

Table 1 shows advantages and disadvantages of aerosol delivery devices. In addition to the characteristics of each device, ultimately the choice is often made by the health care provider, the patient, and availability based on issues such as the formulary. In individual patients, one device may better suit their preference than another.

\section{Pressurized Metered-Dose Inhalers}

The pMDI was the first widely used multi-dose portable inhalational device.1,17,18 Virtually every patient with COPD and asthma either uses or has used a pMDI, most often as albuterol and/or ipratropium. All inhaled drug classes for obstructive lung diseases are available in a pMDI as single or combination products. Yet the pMDI is 


\section{Aerosol Delivery Devices for Obstructive Lung Diseases}

Table 1. Comparison of Inhalers

\begin{tabular}{|c|c|c|}
\hline Device & Advantages & Limitations \\
\hline $\begin{array}{l}\text { Pressurized metered-dose } \\
\text { inhaler }\end{array}$ & $\begin{array}{l}\text { Portable } \\
\text { Compact } \\
\text { Multi-dose device } \\
\text { Dose delivered and particle size relatively } \\
\quad \text { independent of inhalation maneuver } \\
\text { Quick and easy to use for many patients } \\
\text { Suitable for emergencies } \\
\text { Available for many formulations } \\
\text { Not breath-actuated }\end{array}$ & $\begin{array}{l}\text { Requires coordination of inspiration and actuation } \\
\text { Not suitable for young children (without use of a valved holding chamber) } \\
\text { High oropharyngeal deposition (without use of a valved holding chamber) } \\
\text { Some have no dose counter } \\
\text { Propellant required } \\
\text { Need to shake vigorously prior to use } \\
\text { Need to prime if not used recently } \\
\text { Not all medications are available }\end{array}$ \\
\hline Dry powder inhaler & $\begin{array}{l}\text { Portable } \\
\text { Compact } \\
\text { Breath-actuated } \\
\text { Less coordination needed } \\
\text { Short treatment time } \\
\text { Available for many formulations } \\
\text { Dose indicator }\end{array}$ & $\begin{array}{l}\text { Moderate to high inspiratory flow required for most devices } \\
\text { Not suitable for young children } \\
\text { Some devices are single-dose } \\
\text { May not be suitable for emergencies } \\
\text { Some devices are susceptible to environmental humidity } \\
\text { Inability to use with a valved holding chamber } \\
\text { Not all medications are available }\end{array}$ \\
\hline Soft mist inhaler & $\begin{array}{l}\text { Portable } \\
\text { Multi-dose device } \\
\text { Less dependence on inspiratory flow } \\
\text { Slow velocity aerosol } \\
\text { High fine-particle fraction and relatively } \\
\quad \text { high lung deposition } \\
\text { Long plume duration } \\
\text { Less coordination needed } \\
\text { No propellant } \\
\text { Dose indicator } \\
\text { Does not require a spacer (in those }>5 \text { y old) } \\
\text { Suitable for use in children }\end{array}$ & $\begin{array}{l}\text { Device needs to be assembled initially } \\
\text { Not breath-actuated } \\
\text { Need to prime if device not used within last several days } \\
\text { Lack of data in adults regarding delivery through a spacer or valved holding } \\
\text { chamber (data available for children) } \\
\text { Not all medications are available }\end{array}$ \\
\hline Jet nebulizer & $\begin{array}{l}\text { Less coordination needed } \\
\text { Effective with tidal breathing } \\
\text { High doses can be easily administered } \\
\text { Dose modification possible } \\
\text { Combination therapy if drugs compatible } \\
\text { Some are breath-actuated }\end{array}$ & $\begin{array}{l}\text { Cost } \\
\text { Less portable } \\
\text { Pressurized gas source required } \\
\text { Lengthy treatment time } \\
\text { Contamination possible } \\
\text { Device preparation } \\
\text { Not all medications available }\end{array}$ \\
\hline Ultrasonic nebulizer & $\begin{array}{l}\text { Less coordination needed } \\
\text { High doses can be given } \\
\text { Small dead volume } \\
\text { Quiet } \\
\text { Faster delivery than jet nebulizer } \\
\text { Less drug loss during exhalation } \\
\text { Some are breath-actuated }\end{array}$ & $\begin{array}{l}\text { Cost } \\
\text { Need for electrical power } \\
\text { Contamination possible } \\
\text { Prone to malfunction } \\
\text { Possible drug degradation } \\
\text { Does not nebulize suspensions well } \\
\text { Device preparation required } \\
\text { Potential for airway irritation } \\
\text { Not all medications available }\end{array}$ \\
\hline Mesh nebulizer & $\begin{array}{l}\text { Less coordination needed } \\
\text { Effective with tidal breathing } \\
\text { High doses can be easily given } \\
\text { Dose modification possible } \\
\text { Some are breath-actuated } \\
\text { Small dead volume } \\
\text { Quiet } \\
\text { Faster delivery than jet nebulizer } \\
\text { Less drug loss during exhalation } \\
\text { Portable and compact } \\
\text { High dose reproducibility }\end{array}$ & $\begin{array}{l}\text { Cost } \\
\text { Contamination possible } \\
\text { Device preparation required } \\
\text { Not all medications available }\end{array}$ \\
\hline
\end{tabular}




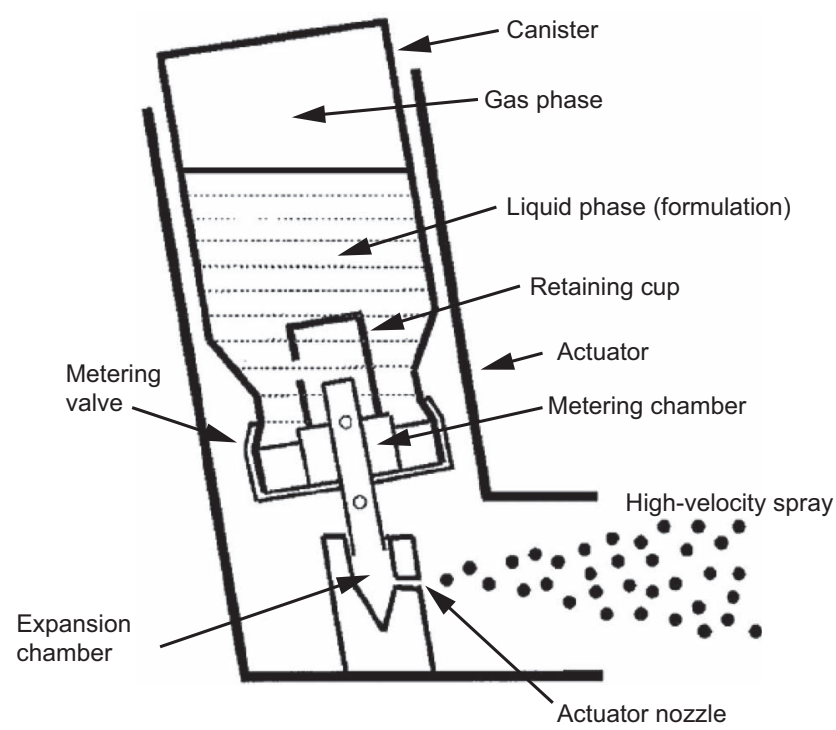

Fig. 3. Components of a pressurized metered-dose inhaler. From Reference 19.

one of the most challenging devices for patients to use correctly. The pMDI has evolved over the decades, with one of the most significant changes being the switch of propellant from CFC to hydrofluoroalkane (HFA). ${ }^{1}$

The pMDI is a multi-dose, pressurized, aluminum canister that, when actuated, delivers drug through a metering valve and orifice (Fig. 3). 3,17,18,20 The formulation is either solution, suspension, or co-suspension and contains other components such as propellant, suspending agents, co-solvents, and surfactants (eg, lecithin or oleic acid, which are soy derivatives). ${ }^{20}$ Excipients infrequently cause adverse effects. Surfactants aid in decreasing particle crystal agglomeration. The interior wall of the canister is coated to decrease adhesion and potential for interaction with components in the formulation. Drug crystals in some pMDIs flocculate, leading to sedimentation. A new formulation, a co-suspension technology, represents a significant advance. It uses phospholipid particles to reversibly attach to drug molecules to provide more uniform suspension, facilitate pharmaceutical compatibility of drug combinations, and provide more consistent drug delivery as well as relying less on the need for shaking prior to use. ${ }^{21}$ Due to differences in boiling temperatures between the drug formulation and room air, when drug reaches the air, it immediately evaporates and aerosolizes small droplets. The aerosol particle size varies among products. Solutions typically have a smaller MMAD than suspensions.

\section{Soft Mist Inhalers}

The SMI (Respimat, Boehringer Ingelheim, Ingelheim am Rhein, Germany) is the newest type of inhaler, initially marketed with ipratropium/albuterol and more recently with long-acting bronchodilators (Fig. 4). ${ }^{22,23}$ The Respimat does not use propellants, as the drug is released via a compressed spring inside the inhaler that pushes drug through a membrane, emitting a small-particle aerosol. ${ }^{22}$ The medication canister is inserted into the inhaler, and both are discarded after all doses are used. It is the only liquid aerosol inhaler that stops emitting doses when the stated number of puffs are reached. Shaking is not necessary prior to using the device.

The MMAD for the Respimat is $\sim 2 \mu \mathrm{m} .{ }^{11}$ The aerosol is released slowly compared to current pMDIs and yields a homogeneous composition..$^{22,23}$ The greater stability of cloud emission from the Respimat is likely to contribute to easier and more convenient use for patients. ${ }^{22}$ Additionally, the relatively long duration over which the dose is released from the Respimat $(\sim 1.2 \mathrm{~s}$ compared with $<0.5 \mathrm{~s}$ from pMDIs) may reduce the coordination required for actuation and inspiration, thus improving the likelihood for greater lung deposition. Based on scintigraphy data, the slower velocity of the Respimat reduces the potential for drug impaction in the oropharyngeal cavity, so that lung deposition is higher (nearly 50\%) and oropharyngeal deposition is lower than that with a pMDI or a pMDI with a spacer. ${ }^{24}$ Although not commonly used, data are now available for administration of the SMI with a valved holding chamber (VHC) with a face mask for use in children. ${ }^{25}$

\section{Spacers and Holding Chambers}

VHCs and spacer devices are used to overcome some of the limitations of pMDIs. ${ }^{17,18,26,27}$ A spacer is a simple tube or extension with no valves to contain the aerosol, whereas a VHC is an extension device with a 1-way valve that, when the attached pMDI is actuated, holds the aerosol until inhalation, although impaction on the inner walls occurs shortly after actuation. Spacers and VHCs allow deceleration of the aerosol plume and, in the case of the latter, trap the aerosol cloud until the patient inhales. However, their availability and coverage by payers is suboptimal in some settings. Although the word spacer is often used for all types of extension add-on devices, these devices are best categorized as either as a spacer or a VHC (Fig. 5). Most VHCs available in the United States are $\sim 200 \mathrm{~mL}$.

Use of these devices can decrease oropharyngeal deposition by $\sim 80-90 \%$ by slowing particle speed and retention of large aerosol particles within the holding chamber. ${ }^{17}$ Compared to a pMDI alone, lung deposition with a spacer is either increased or unchanged, depending on the patients' inhaler technique as well as the particle size. Lung deposition may be increased with large particles via a VHC, but this is less likely with small-particle aerosols, depending on the delay time for inhalation after actuation. 


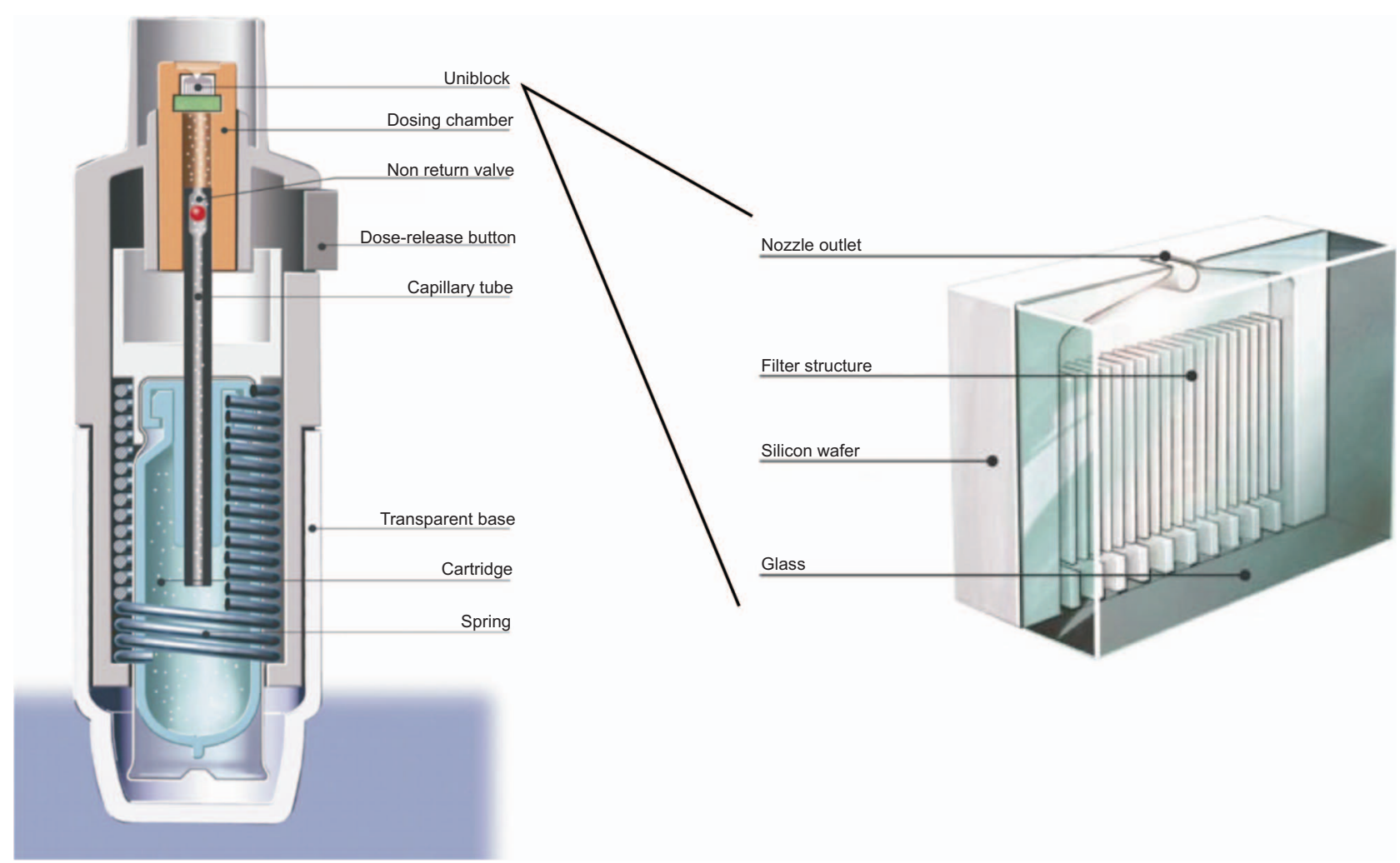

Fig. 4. Soft mist inhaler showing the internal components as well as an enlargement of the uniblock, which helps aerosolize the drug solution from the medication cartridge. From Reference 17.
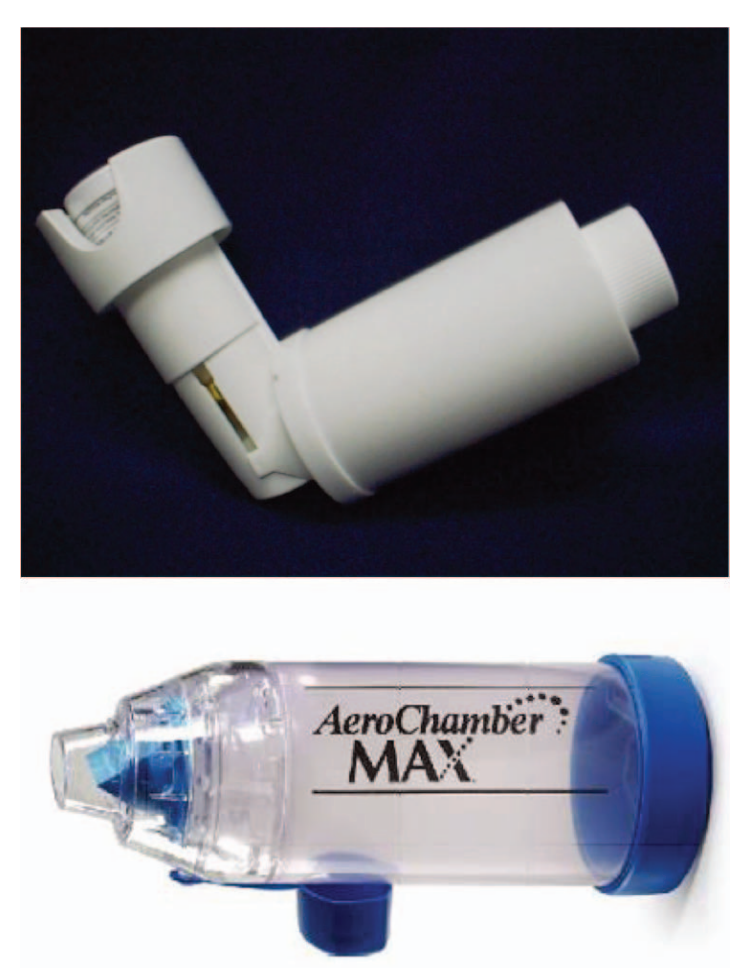

Fig. 5. Spacer (top) and valved holding chamber (bottom). From Reference 17.
Oropharyngeal adverse effects can be decreased with a VHC. This is most important for ICS administered via pMDI, but it is also relevant when the patient does not like the taste of an inhaled medication.

A number of studies have evaluated clinical aspects of the use of a VHC with a pMDI. ${ }^{28-31}$ In one study, single puffs of albuterol through a spacer produced higher plasma levels and greater systemic $\beta$ - 2 responses than either multiple puffs or single puffs with delayed inhalation through the spacer. ${ }^{28}$ The peak blood level of albuterol, reflecting greater lung bioavailability, was $\sim 2$-fold greater for single puffs than for multiple puffs and 1.80-fold greater lung for single puffs without a delay than for single puffs with a 20-s delay between actuation and inhalation. ${ }^{28}$ However, one in vitro study of a small-particle albuterol pMDI suggested a 10-s delay was acceptable. ${ }^{29}$

A study by Leach and Colice ${ }^{30}$ provides insight into the effects of a VHC with pMDIs of different aerosol particle size. In 10 healthy volunteers, radiolabeled beclomethasone dipropionate (BDP) was administered as 2 different products: HFA with smaller aerosol particles, and CFC with larger particles. For both products, the drug was administered with and without a VHC and assessed the effect of breath-hold time and delay of inhalation from the VHC. As shown in Figure 6, the small particle HFA-BDP lung 


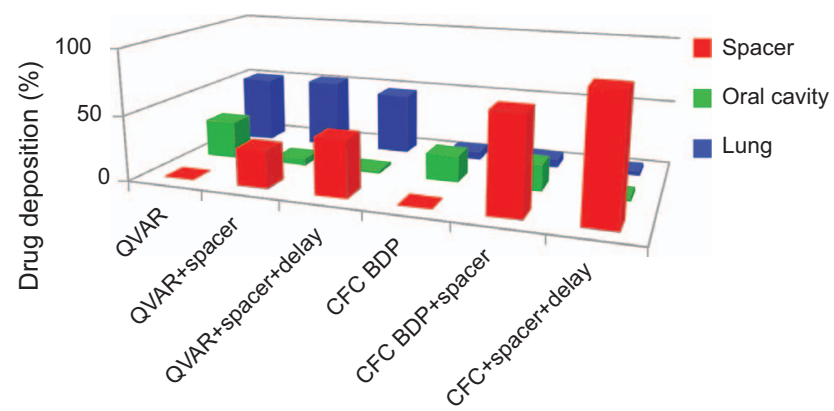

Fig. 6. Delivery of BDP as a small aerosol particle size (QVAR) and as a larger aerosol particle size (BDP) via a CFC inhaler with spacer as well as with a spacer and without a 2-s delay. QVAR = hydrofluoroalkane-beclomethasone dipropionate; CFC = chlorofluorocarbon; BDP $=$ beclomethasone dipropionate. Data from Reference 29.

deposition averaged $\sim 50 \%$ and was affected less by the use of a VHC with or without a delay in inhalation. However, oropharyngeal deposition of HFA-BDP was reduced from $28 \%$ to $4 \%$ with the VHC. Lung deposition with the large particle CFC-BDP was 7\% and was unchanged with the VHC without a delay. A 2-s delay between actuation and inspiration with the spacer reduced lung deposition slightly but reduced oropharyngeal deposition substantially ( $84 \%$ to $3 \%-20 \%$ ) for the large-particle aerosol using the VHC with and without a delay. HFA-BDP lung deposition was dependent on breath-hold because lung deposition with HFA-BDP was reduced by $16 \%$ with a 1 -s breath-hold versus a 10-s breath-hold. The difference was measured in the increased exhaled fraction, confirming that smaller particles need time to deposit and are exhaled if there is a reduced breath-hold. The large particle CFC-BDP lung deposition was less affected by breath-hold. Similarly, another study in healthy volunteers found that adding a VHC to an HFA pMDI delivering small-particle beclomethasone and formoterol aerosol did not affect the systemic exposure of these drugs compared with pMDI alone. ${ }^{31}$ However, the VHC is still useful with small-particle pMDI to decrease the risk of adverse oropharyngeal effects, at least in the susceptible patient, and to also improve technique such as timing of actuation and inhalation. It appears that a slight delay with large aerosol particles through a VHC may decrease oropharyngeal deposition, which is most relevant for ICS.

Aerosol drug particles discharged into a VHC or spacer can be lost to the chamber walls by inertial impaction, gravitational sedimentation, and electrostatic attraction to the interior wall of the device. ${ }^{3,27}$ Devices like the Aerochamber Plus (Monaghan, Plattsburgh, New York) and Vortex (Pari Respiratory, Midlothian, Virginia) are antistatic VHCs. In addition to using an antistatic device, other ways to overcome this problem are to actuate multiple doses into the spacer when new (expensive) and washing in detergent to decrease the static charge. A comparison of normal and ant-static spacers showed differences in albuterol $^{32}$ blood levels and clinical response to albuterol. ${ }^{33}$

In vitro data are also available describing the use of a VHC with a mask with the SMI in children. ${ }^{25}$ Inspiratory flows of $4.9,8.0$, and $12.0 \mathrm{~L} / \mathrm{min}$ in combination with holding times of $0,2,5$, and $10 \mathrm{~s}$ were tested. The flows were selected to be representative of inspiratory flows of children from $6 \mathrm{~m}>5 \mathrm{y}$ old, respectively. There was a modest reduction in absolute delivered dose through a VHC. According to the manufacturer, the dose per kilogram of body weight suggested that the dose of tiotropium Respimat delivered by the AeroChamber Plus Flow-Vu VHC with a mask led to dosing comparable to that of adults without use of a VHC and mask. The fine-particle fraction $(<5 \mu \mathrm{m})$ across the flows was $69-89 \%$ of the delivered dose through the VHC, consistent with the removal of the coarser fraction by the VHC. In contrast, the fine-particle fraction for tiotropium Respimat delivered without a holding chamber typically represents $\sim 50-60 \%$ of the delivered dose. Although not studied in adults, sometimes patients cough with the prolonged aerosol plume with the Respimat, and the use of VHC might decrease that effect. It may also be helpful to decrease oropharyngeal deposition in a patient complaining of dry mouth with the tiotropium Respimat, as well as improve delivery in patients with suboptimal technique.

\section{Dry Powder Inhalers}

DPIs have become very popular in recent years, due in part to the ban on CFCs, which has facilitated the development of new formulations, and they are user-friendly ${ }^{1}$ (Fig. 7). DPI formulations often have excipients because of pharmaceutical formulation issues, and some patients perceive they are not receiving any drug if they do not taste it (eg, lactose excipient). Breath-actuated DPIs may overcome the difficulties with coordination of inhaler actuation and inspiration, but errors still exist, such as inadequate effort.3,17,18,34 The DPI requires each dose to be loaded, whether as a separate capsule or by advancing powder into position by some steps.

DPIs derive the energy for drug delivery by the patient's inspiratory effort, which is greater than that required for a medication administered as a liquid aerosol. . $^{35,36}$ As DPI device technologies have evolved, so have the different approaches to de-agglomerate the powder. Components of the DPI that facilitate de-agglomeration induced by the patient's inspiration include a manifold (eg, Ellipta [GlaxoSmithKline, Brentford, United Kingdom]), cylone (Respiclick [Teva Pharmaceuticals, Petach Tikva, Israel]), mesh (Handihaler [Boehringer Ingelheim] and Neohaler [Sunovion, Marlborough, Massachusetts]), and a spiral chamber (Flexhaler [AstraZeneca, Cambridge, United 


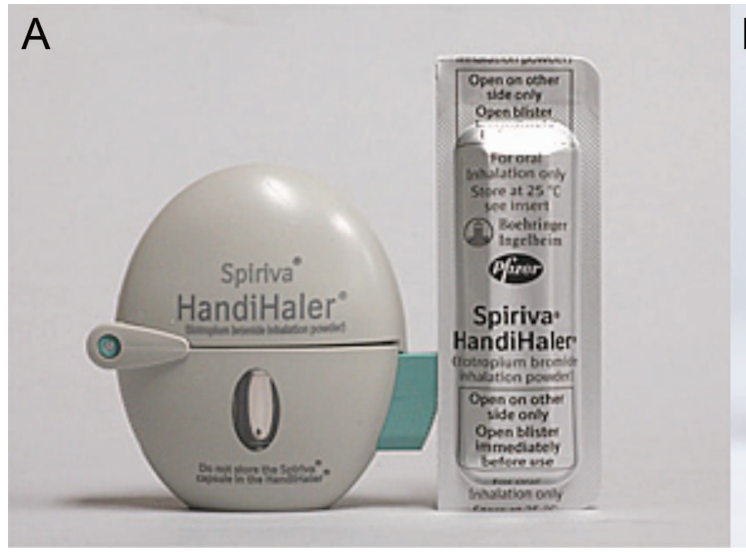

B

Fig. 7. Examples of dry powder inhalers. Handihaler (A); Ellipta (B).

Kingdom]). To produce the optimal MMAD, the drug and excipient agglomerate must be de-aggregated during a forceful inhalation against the internal resistance of the inhaler. ${ }^{35,36}$

The inspiratory effort required to adequately deliver medication varies among DPIs. Some require more effort than others, and some are more susceptible to variations in flow than others. ${ }^{35,36}$ Failure to exhale to functional residual capacity, but not residual volume, before inhaling through a DPI and failure to use a forceful, deep inhalation were 2 of the most common problems with DPIs. The recommended minimum inspiratory effort among different DPI manufacturers has a range of $30-60 \mathrm{~L} / \mathrm{min} . .^{35,36}$

\section{Smart Inhalers}

A unique characteristic of inhalers is the ability to attach or incorporate sensors and other electronic devices to monitor patient adherence, provide feedback concerning disease control, and inform whether the patient used the proper inhaler technique. ${ }^{37,38}$ Digital health data obtained with smart inhalers can provide accurate information about the health of patients and help providers understand possible difficulties that may prevent patients from using their inhaled medication correctly. While devices that can be attached to an inhaler to monitor adherence are not new, what is new are the interfaces with the internet and the complexity of the devices. ${ }^{37}$ Whereas younger patients with asthma are more likely to have the technology (eg, smartphone) to allow for digital health platforms, and they have a good comfort level with such tools, older patients such as those with COPD are less likely to have a smartphone and to be comfortable with the use of such technology. An important issue relates to reimbursement for these devices as well, but one could argue that it might be cost-effective in high-risk, uncontrolled, or non-adherent patients.

Propeller Health is one such new digital health system that has been developed to be attached to most pMDIs,
Diskus (GlaxoSmithKline), and Respimat. ${ }^{39}$ The Propeller device (Propeller Health, Madison, Wisconsin) senses when the patient actuates a dose and is paired wirelessly to a smartphone using Bluetooth technology. This platform could improve outcomes through a combination of analytics, inhaler device sensors, mobile applications, and patient feedback. The system has geospatial abilities and can passively track when and where the patient is using their inhaler. In addition, reminders are sent to each patient to improve adherence. An analytics platform helps identify events or patterns that patients, caregivers, and providers can use to guide management. This system has been studied in the COPD ${ }^{40}$ and asthma populations ${ }^{41}$ to assess impact on disease control.

Other devices are at various stages of development, including inhalers with built-in smart technology. The CareTRX (Teva Pharmaceuticals) device is a simple pMDI actuation monitor that can be attached on top of standard inhaler canisters and provides visual reminders for increased medication adherence. ${ }^{37}$ The CareTRX system, when combined with a smartphone, uses the integrated GPS functionalities to monitor the location of each inhaler use.

Several studies have evaluated the digital health device called Inhaler Compliance Assessment (INCA).42-46 For the Diskus, this device records each dose and determines whether the patient generates an adequate inspiratory effort using audio measurements of flow. One study showed that the subjects with poorly controlled severe asthma who received feedback with the INCA digital device and Diskus inhaler had improved clinical outcomes. ${ }^{46}$

\section{Nebulizers}

A variety of nebulizers are available to generate aerosols for inhaled drug delivery. There has recently been increased interest in the use of nebulizers due to the high cost of HFA formulations. A liquid solution or suspension 


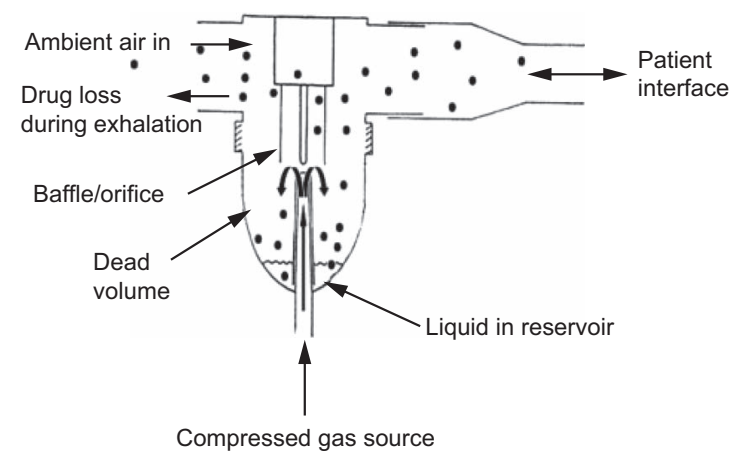

Fig. 8. Drawing of the function of a pneumatic jet nebulizer. From Reference 17.

is added to the nebulizer for each treatment. Traditionally, nebulizers and the drug formulation are marketed separately. Increasingly, formulations introduced to the market are intended for use with a specific nebulizer. Moreover, a variety of nebulizer designs are now available.

\section{Jet Nebulizers}

A jet nebulizer delivers compressed gas through a jet (Fig. 8) ${ }^{17}$ This causes a region of negative pressure, in which a solution or suspension is entrained into the gas stream and is sheared into a liquid film. This film is unstable and breaks into droplets due to surface tension forces. A baffle in the aerosol stream produces smaller particles, and it is further conditioned by factors such as the relative humidity of the carrier gas.

The volume of solution that is trapped inside the nebulizer's dead volume is typically $0.5-1 \mathrm{~mL}$. To reduce dead volume, clinicians and patients commonly tap the nebulizer cup in an effort to increase nebulizer output, but therapy continued past the point of sputtering in an attempt to decrease the dead volume is unproductive and is not recommended. ${ }^{47,48}$ Due to evaporative losses within the nebulizer, the solution becomes increasingly concentrated and cools during nebulization.

An important characteristic of nebulizer performance is its respirable dose, which is the output of droplets from a nebulizer in the respirable range of $1-5 \mu \mathrm{m} .{ }^{17}$ Other characteristics of nebulizer performance include nebulization time, ease of use, ease of cleaning and sterilization, and cost. A short nebulization time that delivers an effective dose is desirable.

Unless designed for a smaller or larger fill volume, the nebulizer should be filled to $4-5 \mathrm{~mL} \cdot{ }^{17,49}$ Because the volume of some unit-dose medications is suboptimal, the formulation should be diluted to a volume to $4-5 \mathrm{~mL}$. The increased nebulization time associated with a greater fill volume can be offset by increasing the flow used to power the nebulizer. Increased flow also decreases the droplet size produced by nebulizers. A flow of $6-8 \mathrm{~L} / \mathrm{min}$ is recommended unless the nebulizer is designed specifically for a flow other than this. Performance differences between nebulizers of different manufacturers and among nebulizers of the same manufacturer has been reported.49-51

In the home setting, jet nebulizers are used with a compressor. Often the nebulizer and compressor are provided as a unit, both from the same manufacturer. The flow and pressure characteristics of compressor/nebulizer units affect nebulizer output. For reasons such as cost, clinicians and patients might not follow recommendations to use compressor/nebulizer combinations. Awad and Berlinski ${ }^{52}$ reported that replacing the nebulizer or compressor with a different brand changed the flow-pressure and aerosol characteristics, with greater effect when the nebulizer was replaced than when the compressor was changed. In another study by Awad et al, ${ }^{53}$ the performance of compressor/nebulizer units was found to deteriorate over time, with some units affected more than others. Others have also reported suboptimal performance of nebulizer compressors..$^{50,54,55}$ Thus, it is important for clinicians to consider compressor performance when assessing patient response to aerosol therapy.

\section{Face Mask Versus Mouthpiece}

Aerosols generated by a jet nebulizer can be administered using either a mouthpiece or a face mask, and a physiologic response can occur with either. Several studies $^{56,57}$ have reported a nearly $50 \%$ reduction in aerosol delivery to the lungs with nasal inhalation, and another study ${ }^{58}$ reported a significantly better increase in $\mathrm{FEV}_{1}$ with a mouthpiece compare to a face mask. The available evidence thus suggests that a mouthpiece is preferred to a face mask for aerosol delivery. There are conflicting data related to the use of a nose clip with aerosol delivery, but the use of a nose clip is not recommended due to patient comfort. 59,60 Nebulizers are often used with face masks when the patient is acutely ill or uncooperative. The face mask seal can impact facial and eye deposition of aerosol. ${ }^{61-65}$ The nebulizer can be inserted straight into the mask (top-loaded) or vertically from below (bottomloaded). Front-loaded nebulizers are more efficient but may favor eye deposition. ${ }^{66}$ When the mask was modified with vents and specialized cutouts in the region of the eyes, facial and eye deposition was minimized.

Aerosol delivery to a distressed child is minimal if the child is crying. ${ }^{67}$ An alternative technique for aerosol delivery to the pediatric patient is blow-by, in which the clinician aims the aerosol flow toward the patient's face instead of applying a mask. Rubin suggested that blow-by is a waste of time, a waste of money, and an unnecessary irritation for the distressed child. ${ }^{68}$ However, Smaldone et al ${ }^{66}$ reported that pediatric aerosol delivery was a func- 
A
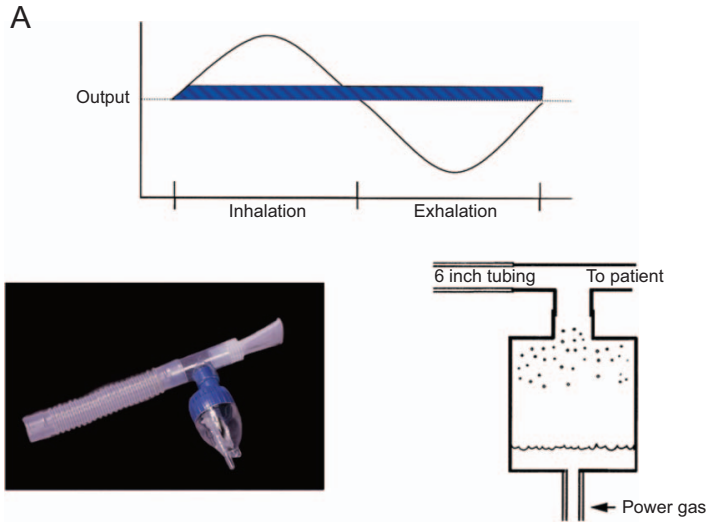

C
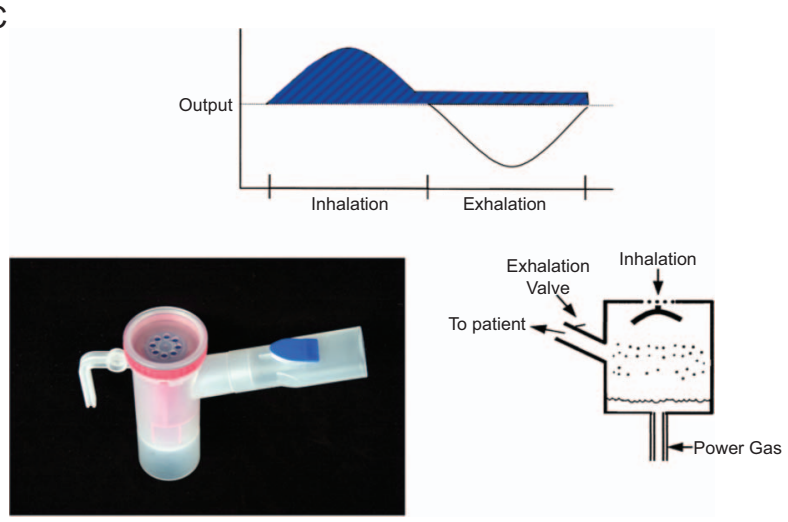

B
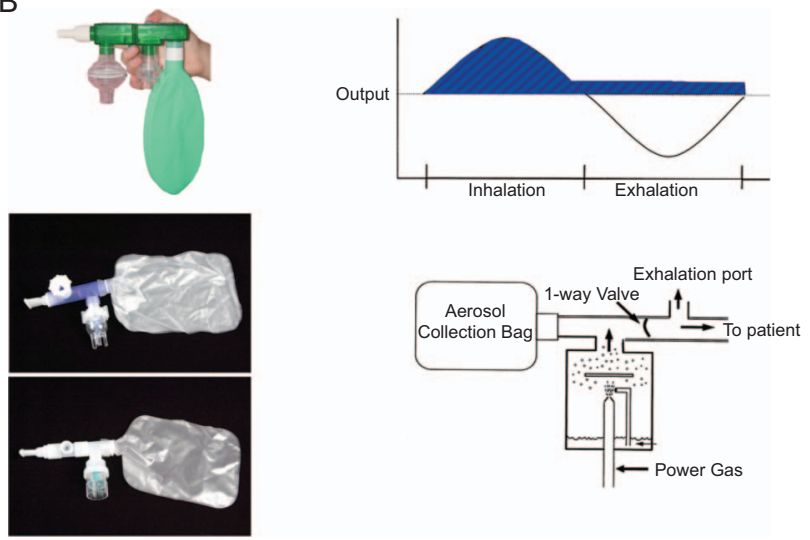

D
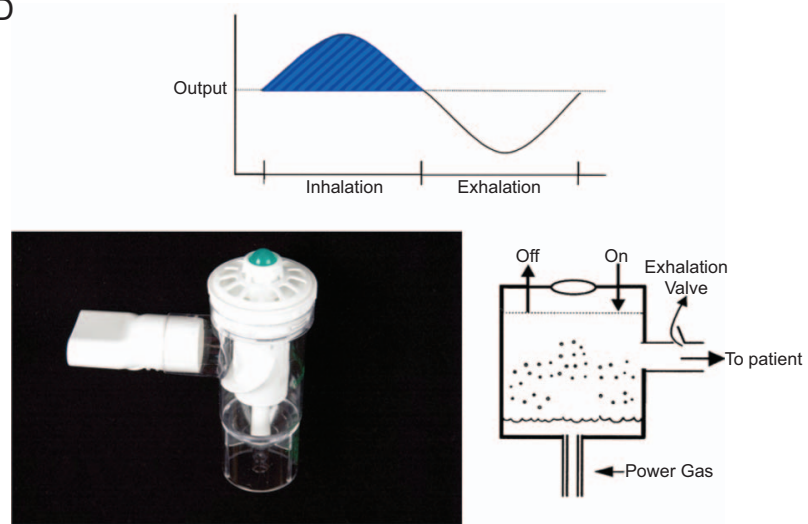

Fig. 9. Nebulizer designs. A: Jet nebulizer with reservoir tube. B: Nebulizer with aerosol collection bag. C: Breath-enhanced nebulizer. D: Breath-actuated nebulizer. In each case, the aerosol output of the device is indicated by the striped area. From Reference 17.

tion of blow-by distance from the face and nebulizer efficiency. They suggest that, in uncooperative children, blow-by can be effective with the appropriate nebulizer system.

\section{Designs to Decrease Aerosol Waste During Exhalation}

The traditional jet nebulizer has a constant output during the inspiratory and expiratory phases. This results in drug loss during exhalation, and several designs can be used to minimize this loss. An inexpensive approach is to attach corrugated tubing to the nebulizer T-piece as a reservoir (Fig. 9). ${ }^{69,70}$ Another approach uses a bag to store aerosol during exhalation. ${ }^{71-76}$ Breath-enhanced nebulizers use a mainstream or open-vent design to boost nebulizer output during inhalation. Several studies reported greater pulmonary deposition and shorter treatment time with this design compared with a conventional nebulizer. ${ }^{77-82}$

Aerosol waste during the expiratory phase can be eliminated with the breath-actuated dosimetric design. ${ }^{83} \mathrm{Sev}-$ eral studies have reported reduced drug waste with this nebulizer design. ${ }^{57,76,80,84-86}$ Arunthari et al ${ }^{86}$ reported bet- ter subject and respiratory therapist satisfaction with the use of a breath-actuated nebulizer. Sabato et al ${ }^{87}$ reported that, although use of a breath-actuated nebulizer did not reduce the time in the emergency department for pediatric subjects with asthma, it was associated with a significantly improved clinical asthma score, decreased admissions, and decreased breathing frequency.

\section{Mesh Nebulizers}

Mesh nebulizers use a mesh or plate with multiple apertures to produce an aerosol (Fig. 10). ${ }^{88-90}$ Mesh nebulizers have very low residual volume, fast treatment time, and the ability to nebulize a variety of solutions and suspensions. These devices are powered by batteries or electricity, and an external gas flow is not required.

With active mesh nebulizers (vibrating mesh), a vibrational element contracts and expands, moving a domed aperture plate with $>1,000$ tapered holes. ${ }^{91}$ The holes are larger on the liquid side and smaller on the side from which the droplets emerge. Passive mesh nebulizers use a piezoelectric crystal that vibrates a transducer horn inter- 

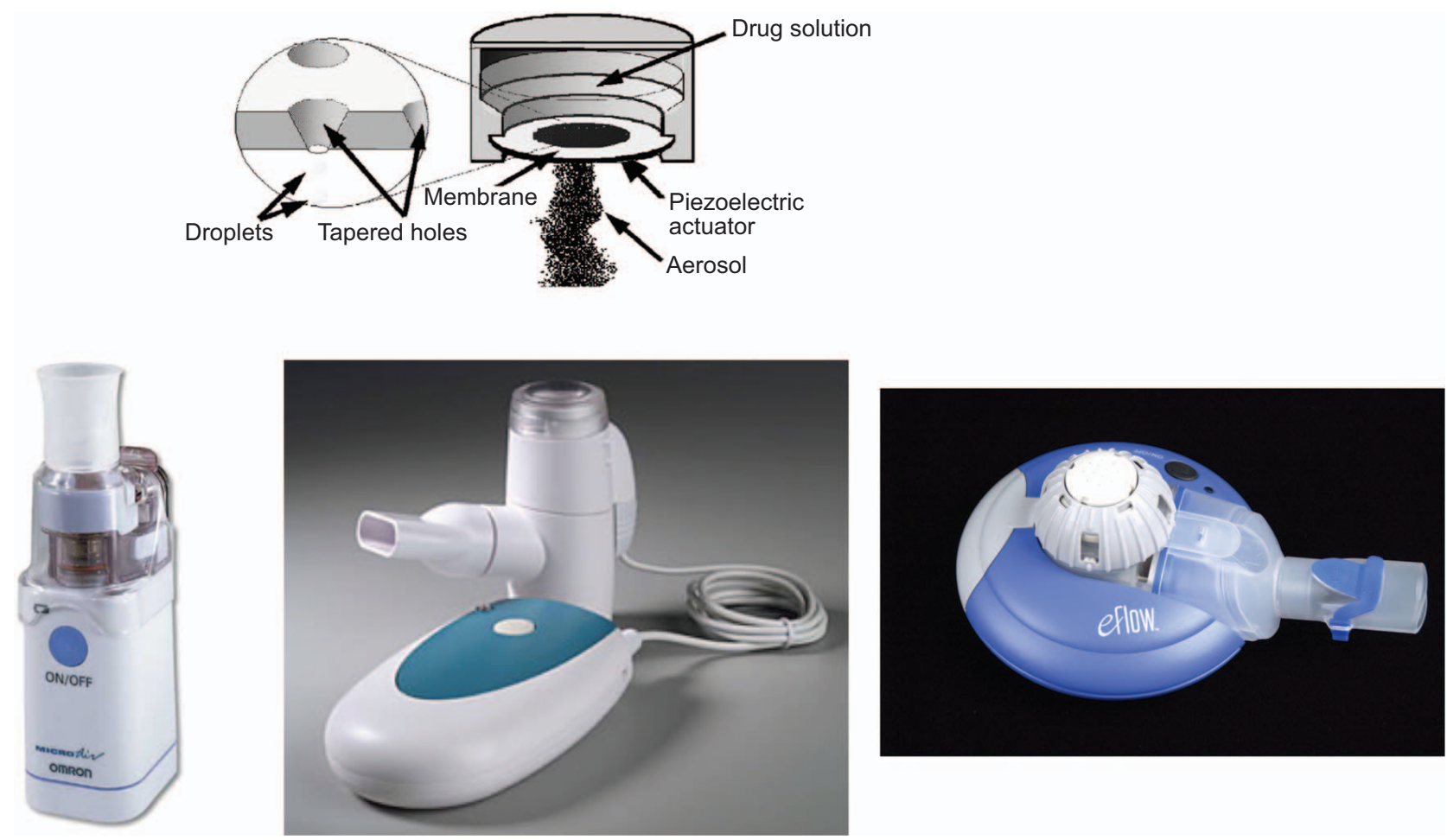

Fig. 10. Mesh nebulizer. Top: Principle of operation of the device. Bottom: Representative of commercially available devices. From Reference 17.

acting with the liquid formulation and a static aperture plate, which pushes fluid through the mesh. ${ }^{91}$ For both active and passive designs, the drug is placed in the reservoir of the nebulizer above the aperture plate. Particle size and aerosol flow are determined by the exit diameter of the holes on the aperture plate. There is the potential for the pores of the nebulizer to become clogged with some suspensions or viscous drugs. The reliability of vibrating mesh nebulizers has also been questioned, with one report finding that nebulization was often randomly interrupted with a wide range of retained volumes..$^{92}$

Aerosol delivery from a mesh nebulizer has been reported to be greater than that of a jet nebulizer. ${ }^{79,93,94}$ Delivery efficiency of a mesh nebulizer may be $>3$ times that of jet nebulizers, and thus drug doses may need to be adjusted. ${ }^{94} \mathrm{~A}$ holding chamber can be used with the mesh nebulizer to collect aerosol during exhalation, further increasing the dose on the subsequent inhalation. ${ }^{94}$ Mesh nebulizers are more expensive than jet nebulizer/compressor systems. Mesh nebulizers are available for use by ambulatory patients, and systems are also available for use during invasive and noninvasive ventilation. Aztreonam (an antibiotic for cystic fibrosis) and glycopyrrolate (a long-acting muscarinic antagonist for COPD) are examples of FDA-cleared drugs for inhalation using a mesh nebulizer.

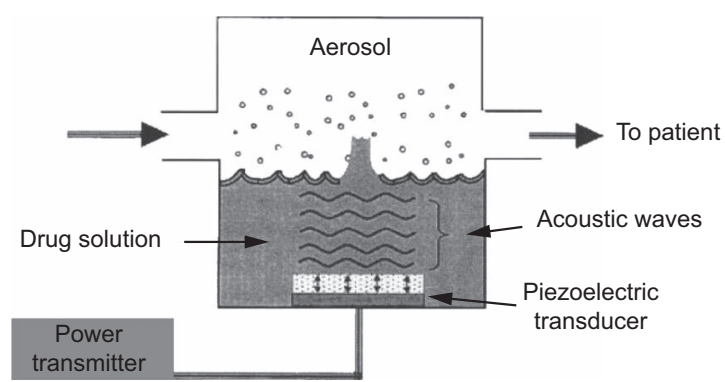

Fig. 11. Function of an ultrasonic nebulizer. From Reference 168.

\section{Ultrasonic Nebulizers}

Ultrasonic nebulizers convert electrical energy to highfrequency ultrasonic waves. The ultrasonic waves are transferred to the surface of a liquid, thus producing an aerosol (Fig. 11). Small-volume ultrasonic nebulizers are commercially available for delivery of inhaled bronchodilators. Their cost is greater than that of jet nebulizer/compressor systems but comparable to that of mesh nebulizers. A drug/device combination that uses an ultrasonic nebulizer is the treprostinil/Tyvaso system. ${ }^{95}$ Use of these devices has been hampered by their tendency for mechanical malfunction. A potential issue with the use of ultrasonic nebulizers is the possibility for drug inactivation by the ultrasonic waves, although this has not been shown to occur 


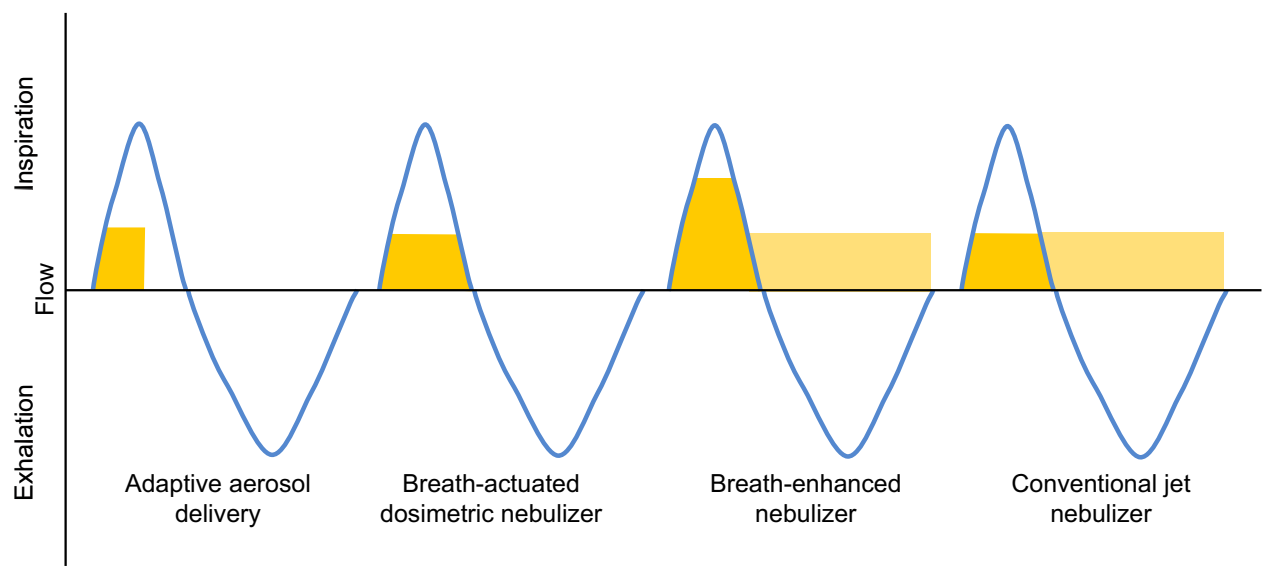

Fig. 12. A schematic representation of flow and inspiration/expiration ratios of 4 different types of nebulizer. The drug available for inhalation is indicated by the dark shaded areas, whereas the lightly shaded areas indicate losses to the surrounding air.

with common aerosol medications. The ultrasonic nebulizer is inefficient in nebulizing a suspension. ${ }^{96}$

\section{Smart Nebulizers}

Smart nebulizers have recently become available for individualized controlled inhalation, which allows a bolus aerosol inhalation technique adjusted to the patient's breathing pattern or lung function. ${ }^{97,98}$ These systems combine nebulizer technology, flow and/or pressure sensors, and a microprocessor.

One type of smart nebulizer is adaptive aerosol delivery (I-neb, Philips, Murraysville, Pennsylvania). ${ }^{99-103}$ This device analyzes the patient's breathing pattern to determine the timing of the aerosol pulse during inhalation (Fig. 12). An aerosol is generated using a mesh nebulizer. The pressure changes of the initial breaths are used to determine the starting point for aerosol delivery during inhalation. Monitoring of the preceding 3 breaths continues throughout the treatment, and the device continually adapts to the patient's breathing pattern. The adaptive aerosol delivery system can be operated in either the tidal breathing mode or the target inhalation mode. The breathing mode is selected by using a specific mouthpiece, which is detected by the electronics in the device. In the tidal breathing mode, the patient breathes tidally though the mouthpiece. In the target inhalation mode, the patient is provided feedback to take a slow and deep breaths. There are several potential benefits of adaptive aerosol delivery. The aerosol is frontloaded in the breath, which should maximize parenchymal deposition and minimize dead-space deposition. The device is breath-actuated, which eliminates drug waste during the expiratory phase.

The AKITA (Vectura, Chippenham, United Kingdom) is another smart nebulizer system. It can be used with either a jet nebulizer of a mesh nebulizer. For the jet nebulizer, it controls a compressor so that the dose delivery is targeted to a specific region of the lungs. Information about the patient's lung function information can be entered into the system and used to individualize drug delivery. When used with a mesh nebulizer, this system deposits $\sim 70 \%$ of the nominal nebulizer fill to the lungs. ${ }^{97,98}$

\section{Continuous Aerosol Delivery}

Continuous aerosolized bronchodilators are occasionally used in the treatment of acute asthma. Typical doses for continuous albuterol range from 5 to $15 \mathrm{mg} / \mathrm{h} .{ }^{104}$ The available evidence suggests that this therapy is safe and at least equally effective as intermittent nebulization. ${ }^{18,105}$ Several nebulizer configurations have been used for continuous nebulization including frequent refilling of the nebulizer, use of a nebulizer and infusion pump, or use of a large-volume nebulizer. ${ }^{17}$ Systematic reviews suggest that either frequent intermittent nebulization or continuous nebulization are appropriate in severely dyspneic patients in the emergency department or ICU.18,106 Due to the risk of arrhythmias, hypokalemia, and tremor, patients receiving high dose inhaled beta agonists should receive treatment in a monitored unit. The benefit for continuous nebulization seems to be greatest for patients with most severe asthma. ${ }^{106}$ Although pulmonary function and asthma symptom scores are similar for continuous and intermittent nebulization of short-acting $\beta$-agonists, the time requirements for staff are less for continuous nebulization than for intermittent nebulization. ${ }^{18}$ Continuous nebulization of $\beta$-agonists might reduce hospital admission rate from the emergency department. ${ }^{106}$ 
Table 2. FDA-Cleared Formulation-Nebulizer Combinations

\begin{tabular}{lll}
\hline \hline \multicolumn{1}{c}{ Formulation } & \multicolumn{1}{c}{$\begin{array}{c}\text { Brand } \\
\text { Name }\end{array}$} & \multicolumn{1}{c}{ Nebulizer } \\
\hline $\begin{array}{l}\text { Tobramycin } \\
\text { Dornase alfa }\end{array}$ & $\begin{array}{l}\text { Tobi } \\
\text { Pulmozyme }\end{array}$ & $\begin{array}{l}\text { Pari LC } \\
\text { Hudson T Up-draft II, Marquest } \\
\text { Acorn II, Pari LC, Durable } \\
\text { Sidestream, Pari Baby }\end{array}$ \\
& & $\begin{array}{l}\text { Marquest Respirgard II } \\
\text { Pentamadine }\end{array}$ \\
$\begin{array}{l}\text { Ribavirin } \\
\text { Iloprost }\end{array}$ & VebuPent & Small Particle Aerosol Generator \\
Aztreonam & Ventavis & I-neb \\
Treprostinil & Cayston & Altera \\
Glycopyrrolate & Tyvaso & Tyvaso Inhalation System \\
\hline
\end{tabular}

\section{Use of Heliox With Nebulizers}

Heliox is a gas mixture of helium (60-80\%) and oxygen that is used to improve flow in patients with partial airway obstruction. ${ }^{107}$ The results of a meta-analysis support the use of heliox-driven $\beta$-agonist nebulization for children and adults with acute asthma. Heliox-driven nebulization produced a significant decrease in the risk of hospitalization (odds ratio $0.49,95 \%$ CI $0.31-0.79$ ). The benefit was greatest for subjects with severe and very severe asthma. ${ }^{108}$

Several issues should be considered when delivering aerosolized $\beta$ agonists with heliox. Hess et al ${ }^{109}$ found that the flow of $80 \%$ helium $/ 20 \%$ oxygen must be increased by $\sim 50 \%$ to generate optimally sized respirable particles. Corcoran and Gamard $^{110}$ found that, compared to $10 \mathrm{~L} / \mathrm{min} \mathrm{O}_{2}, 12 \mathrm{~L} / \mathrm{min}$ of $70 \%$ helium:30\% oxygen is needed to generate an equivalent mass of particles $<3 \mu \mathrm{m}$. O'Callaghan et al ${ }^{111}$ reported that, for a vibrating mesh nebulizer, the total output was significantly higher when heliox was used as the delivery gas compared to air; when a breath-enhanced nebulizer was used, a much higher driving flow of heliox was required to deliver a similar dose of drug compared to air. Another issue relates to entrainment of room air and consequent dilution of the heliox mixture. If heliox is used to power the nebulizer, but heliox is not provided in the additional gas that is entrained, the dilution with air may decrease the resulting inspired helium concentration and reduce any potential benefit of the heliox. Thus, a closed system or one with sufficiently high flows should be used to minimize air entrainment.

\section{Nebulizer/Formulation Combinations}

Drug formulations were traditionally nebulizer agnostic. That is, any formulation could be used with any nebulizer, and the drug manufacturers and nebulizer manufacturers were not related. Increasingly, drug solution formulations have been FDA-cleared for a specific nebulizer (Table 2). When the formulation has been cleared for use with a specific nebulizer, that combination should be used in practice to assure correct dosing. Another issue related to the use of nebulizers is the compatibility of formulations that can be mixed together in the nebulizer. Clinicians and patients prefer to mix formulations to decrease the time required for treatment. Before mixing solutions of various formulations in the nebulizer cup, however, the clinician must be certain that the combination is compatible. ${ }^{112}$

\section{Nebulizer Applications in Critical Care}

Nebulizers are commonly used with critically ill patients. ${ }^{94}$ Detailed reviews have been published elsewhere related to nebulizer use during invasive ventilation, ${ }^{113,114}$ noninvasive ventilation, ${ }^{114,115}$ with high-flow nasal cannula, ${ }^{115}$ and with tracheostomy. ${ }^{116}$

\section{Cleaning and Disinfection of Nebulizers}

Patients should be taught how to disinfect nebulizers used in the home. After each treatment, the patient should shake the remaining solution from the nebulizer cup. The nebulizer cup should be rinsed with either sterile or distilled water and left to air dry on an absorbent towel. Once or twice a week, the nebulizer should be disassembled, washed with soapy tap water, and disinfected with 1 part distilled white vinegar in 3 parts hot water for $1 \mathrm{~h}, 1$ part household bleach and 50 parts water for $3 \mathrm{~min}, 70 \%$ isopropyl alcohol for $5 \mathrm{~min}, 3 \%$ hydrogen peroxide for $30 \mathrm{~min}$, or a quaternary ammonium soak for $10 \mathrm{~min}$. After any one of these processes, the nebulizer should be rinsed with either sterile or distilled water. Some nebulizers can be disinfected in boiling water or in a dishwasher. The manufacturer's specific instructions should be consulted for the recommended cleaning and disinfection procedures. Jet nebulizers have been reported to function correctly for repeated uses provided they are cleaned after each use, rinsed, and air dried. ${ }^{117}$ Nebulizers used in the hospital are usually disposable, single-patient-use. They should be changed at the conclusion of the dose, every $24 \mathrm{~h}$, or when visibly soiled. Nebulizers should not be rinsed with tap water, but may be rinsed with sterile water and allowed to dry between treatments.

\section{Clinical Studies Supporting the Impact of Aerosols}

Factors that influence optimal delivery of inhaled drug therapy in subjects with obstructive lung diseases include the device, drug formulation, and patient characteristics such as cognition, disease severity, and clinical status of the patient, all of which can influence patient outcomes. ${ }^{3,17,18}$ In patients with asthma or COPD, incorrect pMDI technique has been associated with a $50 \%$ increased risk of hospitalization as well as increased emergency de- 
partment visits and oral corticosteroid use. ${ }^{118}$ Clinical and real-world studies in subjects with obstructive lung disease show differences in outcomes and adverse effects associated with less efficient DPIs. ${ }^{119-124}$ When compared to the same drug administered with a pMDI, the Seretide Accuhaler (GlaxoSmithKline) was shown to have a higher risk of exacerbations in subjects with asthma and COPD as well as oropharyngeal adverse effects, presumably related to differences in lung and oropharyngeal deposition between the less efficient Accuhaler and pMDI. ${ }^{120-122}$

In a study of pediatric subjects with asthma, it was found that formoterol DPI achieved a greater increase in $\mathrm{FEV}_{1}$ post-exercise when inhaled at a higher inspiratory flow. ${ }^{124}$ Another study evaluated the effect of beclomethasone HFA (smaller MMAD) on spirometry and computed tomography in adult asthmatics. There was less air trapping in subjects receiving the smaller MMAD, whereas symptoms and $\mathrm{FEV}_{1}$ were not different between the formulations with different MMAD. 123

Several studies have found that impaired peak inspiratory flow (ie, below the minimum necessary for DPI) occurred in a third or more of subjects with COPD exacerbations requiring hospitalization. Loh et al ${ }^{125}$ reported that subjects with impaired peak inspiratory flow were at a greater risk of all-cause 90-d re-hospitalization, whereas this was not found in the study by Sharma. ${ }^{126}$ The decrease in inspiratory flow persists after exacerbations, where it was reported the post-bronchodilator inspiratory capacity and inspiratory reserve volume was increased by $20 \%$ and $37 \%$, respectively, between day 2 after hospital admission and 6 weeks later in subjects with COPD exacerbations. ${ }^{127}$ Broeders et al ${ }^{128}$ reported that peak inspiratory flow measured with the InCheck DIAL (Alliance Tech Medical, Granbury, Texas) increased between $17 \%$ and $22 \%$ between hospital admission and 5 weeks later when subjects were clinically stable in the out-patient setting.

Small particle size decreases oropharyngeal deposition and local adverse effects compared to the same drug with a larger aerosol size. ${ }^{6,122,129}$ Studies in subjects with asthma and COPD indicate greater improvements in small-airway function with small-particle aerosols, which lends support to this benefit. ${ }^{130-135}$ However, it is possible that particles that are too small (ie, $<1 \mu \mathrm{m}$ ) may be less efficacious than particles of a medium size. Two studies reported that $\mathrm{FEV}_{1}$ improved to a greater extent with particle sizes of $\sim 3 \mu \mathrm{m}$ than with particles $\sim 1.5 \mu \mathrm{m} .{ }^{136,137}$ It is important to recognize that spirometry does not precisely measure function in the small airways, which means spirometry is not a good estimate of the effects of small-particle aerosols in the respiratory zone. MRI with hyperpolarized gas might provide a better scientific understanding in this area, but this is largely in early stages of clinical research application. ${ }^{8}$
Increased lung deposition might be expected to be associated with greater systemic effects, such as the suppression of cortisol production with ICS. However, short-term clinical trials have not documented increased risk of systemic effects with a small-particle ICS, ${ }^{129-131}$ or with a small-particle ICS/long-acting $\beta$ agonist (LABA) combination formulation. ${ }^{133}$ Treatment with small-particle HFA-pMDI, ICS/LABA, and nebulizer-based aerosols has resulted in less suppression of the hypothalamic-pituitaryadrenal axis than has treatment with an equipotent dose of large-particle ICS/LABA pMDI. ${ }^{133}$ However, long-term studies are needed to better understand the potential risks for systemic adverse effects that may occur with increased lung deposition achieved with small particle sizes. The use of small-particle aerosol therapy may decrease the need for a VHC or spacer because of the reduced impaction of particles in the oropharynx.

\section{Inhalation Device Selection}

There are many challenges with the use of inhalers and nebulizers, and no one device suits all patients. , $^{317,18}$ Challenges range from difficulties related to lung disease severity to physical impediments. In terms of device selection and adherence, patient engagement and satisfaction are important to consider. Each device has different technical properties, so a personalized approach to the selection of the most appropriate device is recommended to achieve desired clinical outcomes for each patient. If an inhaler does not produce optimal results, the patient may become non-adherent. Furthermore, the use of multiple types of devices can present challenges to patients. Some strengths and weaknesses of different inhalation devices are shown in Table 1.

Patient factors to consider in device selection include disease status, physical and mental capabilities, past experiences with inhalers, preferences and satisfaction with their inhalers. Disease-related factors include respiratory muscle weakness, air trapping, airway narrowing, and worsening symptoms such as during an exacerbation. ${ }^{3,17,18}$ Elderly patients are more likely to have physical impediments such as arthritis or cognitive impairments such as dementia. Patient preferences for different inhaler types include ease of use, portability, compact design of the device, noise, taste, treatment time, and convenience. A real-world observational study reported that the higher the satisfaction level of the subject with their device, the more likely they were to adhere to therapy and have better outcomes (eg, improved quality of life, fewer acute care visits). 138

In addition to patient factors, choice of inhaler depends on other factors, such as medication(s) availability in particular inhalers, the need for use of a spacer or VHC, required inhaler technique, and health insurance coverage. 
The first step in device selection may be to determine the formulary status of the medication prescribed. If not, this could lead to the first inhalational technique error the patient can make, which is not acquiring the inhaler.

Of the multi-dose inhalers, the pMDI is the most difficult to use correctly, particularly for the elderly patient with COPD. DPI breath-activated devices tend to be easier to use. Multiple-step DPIs, such as those requiring insertion of capsules, are slightly more complicated than those with doses already loaded. The target inspiratory flow for the pMDI and SMI is approximately $30 \mathrm{~L} / \mathrm{min}$, with a slow inhalation over 3-5 s, and the majority of patients are able to achieve this. Due to technique differences with the SMI compared to other inhalers, it should be determined whether the patient is able to properly use the device.

Although DPIs are relatively simple to use, adequate inspiratory flow is important. The minimum peak inspiratory flow ranges from $30 \mathrm{~L} / \mathrm{min}$ for the Handihaler and Breezhaler (Novartis, Basel, Switzerland) to $60 \mathrm{~L} / \mathrm{min}$ for the Diskus and Ellipta. ${ }^{35,36}$ The Handihaler is a high-resistance DPI, whereas the Ellipta, Turbuhaler (AstraZeneca), and Diskus are medium-resistance DPI, and the Breezhaler is a low-resistance DPI. Patient-related impediments to achieving adequate inspiratory flow in patients with COPD include elderly age, female gender, and stature. ${ }^{42,139,140}$ Ideally, the peak inspiratory flow can be measured to ensure the patient achieves an acceptable value, recognizing that this measure may drop with worsening symptoms.

Some in vitro studies indicate that the fine-particle dose from DPIs is reduced when inspiratory flow is $<60 \mathrm{~L} / \mathrm{min},{ }^{141-144}$ whereas other studies show little effect of flow. ${ }^{145,146}$ Diskus lung delivery may be suboptimal with a peak inspiratory flow $<60 \mathrm{~L} / \mathrm{min}$. In a study of healthy volunteers, a decrease in the peak inspiratory flow from $60 \mathrm{~L} / \mathrm{min}$ to $30 \mathrm{~L} / \mathrm{min}$ resulted in a $30 \%$ decrease in blood levels of albuterol and fluticasone, ${ }^{43}$ suggesting decreased lung delivery. ${ }^{9}$ In a study conducted in an out-patient research setting, using an instrumented Ellipta inhaler, severe to very severe subjects with COPD had shorter inspiratory times and tended to have impaired inspiratory flow $(<60 \mathrm{~L} / \mathrm{min}){ }^{144}$ Decreased inspiratory flow has been observed when patients with COPD are clinically stable ${ }^{36,140,143,147}$ and during exacerbations requiring hospitalization. ${ }^{125,126,128}$ One study in subjects with COPD recently discharged from the hospital were instructed in the use of a Diskus inhaler with the INCA smart inhaler device. ${ }^{45}$ The most common subject error with the DPI was an inadequate inspiratory flow. Notably, $20 \%$ of the subjects had a zero inspiratory flow, as they never used the device over the 1-month study period.

Another factor that might affect inspiratory flow in the patient with COPD is the position of the patient when using the DPI (standing, sitting, supine). Air-flow obstruc- tion in COPD increases resistance to air flow during expiration and inspiration, although it is more evident during expiration. ${ }^{148}$ It has also been shown that functional residual capacity was lower in a supine position than in a standing position. ${ }^{149}$ A study in subjects with COPD and air trapping showed that the inspiratory flow was reduced. ${ }^{150}$ Therefore, it is possible that, under certain conditions, lung deposition that depends on a strong inspiratory effort could be altered by the physical position and impaired inspiratory capacity of the patient with COPD. Using $\gamma$-scintigraphy in healthy volunteers, it was found that inhalation in a supine posture shifts relative deposition from the alveolar to the bronchial airways compared to the seated posture. ${ }^{151}$ This was suggested to be due to changes in functional residual capacity, airway size, and changes in the regional distribution of ventilation between postures. Additional research is needed to better understand this issue.

DPIs have greater susceptibility to environmental humidity, ie, some products under certain circumstances can be affected. ${ }^{152-154}$ If moisture gets into the powder, it decreases de-agglomeration and therefore increases MMAD as well as decreases fine-particle fraction and fine-particle dose. The excess moisture in the aerosol powder does not affect the total dose delivered by the DPI; rather, it affects the fine-particle dose. From the time that the drug is manufactured and stored, then dispensed, and during the variable usage and storage by the patient, the dry powder may be exposed to excessive humidity. If everything is done correctly, the exposure to moisture is usually minimal. Some products are sold in foil packaging with desiccants (eg, Ellipta), ${ }^{155}$ and others may not, depending on the country of origin (Accuhaler). ${ }^{156}$ The FDA requires testing under certain temperatures, humidity, and time periods for all inhalers, and this is especially relevant for DPIs.

Storage of fluticasone propionate/salmeterol Accuhaler (not in foil pack) and budesonide/formoterol Turbuhaler at $40^{\circ} \mathrm{C}$ and $75 \%$ relative humidity over 3 months led to a $42 \%$ decrease in the in vitro fine-particle dose of fluticasone propionate for the Accuhaler, with only minimal change for the Turbuhaler. ${ }^{153}$ Storage of the Accuhaler device at $25^{\circ} \mathrm{C} / 30 \%$ relative humidity over 3 months led to a $10 \%$ decrease in fine-particle dose of fluticasone propionate. Corroborating the in vitro findings, at $40^{\circ} \mathrm{C}$ and $75 \%$ relative humidity, the area-under-the-serum-concentration curve after fluticasone propionate/salmeterol administration in healthy volunteers decreased by $\sim 40 \%$ for the 2 ingredients for the Accuhaler and changed minimally for the Turbuhaler. A study evaluating the effects of humidity and temperature on the fluticasone propionate/salmeterol Spiromax and budesonide/formoterol Turbuhaler reported a slight decrease $(9.3 \%$ and $10.3 \%$, respectively) in fine-particle dose of the steroid components in vitro after 1.5 months of storage at $40^{\circ} \mathrm{C} / 75 \%$ relative humidity. ${ }^{154}$ The fine-particle dose of budesonide from budesonide/formoterol 
Easyhaler (available in Europe) decreased by $59 \%$ at $40^{\circ} \mathrm{C} /$ $75 \%$ relative humidity and by $38 \%$ at $25^{\circ} \mathrm{C} / 75 \%$ relative humidity, suggesting that excess moisture alone can affect fine-particle dose. Non-adherent patients are the ones most apt to encounter problems with moisture as they use their inhalers for longer than the recommended usage period (eg, the Twisthaler [Merck, Kenilworth, New Jersey] is to be discarded $45 \mathrm{~d}$ after removing from the foil pack). DPIs that use a capsule inserted into the device are less susceptible; however, if the patient removes the capsule from the foil packaging and does not use it within a short time period, moisture starts penetrating the capsule. ${ }^{157}$

\section{Patient Education}

Among the most common chronic diseases, arguably the most complicated types of drug therapies for patients to self-administer are injectables for diabetes mellitus and inhaled medications for obstructive lung diseases. Whereas diabetics are taught how to administer injectables, such education is often lacking for inhaled medications in patients with asthma and COPD. There are numerous reasons for this, including a lack of well-established mechanisms to reimburse health care providers for this teaching, a lack of providers being adequately trained, and it does not appear to be complicated. Recently, a survey of pulmonologists and patients found that the minority of subjects received education from providers and that providers were not highly comfortable with their knowledge with certain devices. ${ }^{158}$ Only $40 \%$ of pulmonologists reported that device characteristics influenced their prescribing of inhalers. Part of the problem is the lack of incorporating inhalation therapy training in pulmonary and other specialty fellowship training programs.

Health care professionals are central to the management of patients with COPD and asthma, whether it is the physician, respiratory therapist, nurse, pharmacist, or other provider. The wide range of drug and inhaler combinations increases the complexity of inhaler choice for providers and patients. Many providers cannot describe all of the steps involved or demonstrate correct inhaler use for all of the inhalers they prescribe. ${ }^{159,160}$

The most effective patient training technique has been established as verbal instruction combined with a demonstration by the provider and then a reciprocal demonstation by the patient. This is challenging due to the lack of an available device that the patient can use to demonstrate adequate technique. Repetitive instruction over time increases the proportion of patients who maintain the correct technique at follow-up visits. ${ }^{161,162}$ If a patient is unable to use one device, perhaps another should be chosen. But there are limits, such as how to teach a patient with major cognitive impairment to use an inhaler. If poor technique persists, it is essential to elucidate from the patient the challenges they are experiencing and then address any potential lack of understanding around the need for medication and adherence. A review evaluated a range of interventions and determined that, although many studies demonstrate a post-intervention improvement in the number of individuals with correct inhaler technique, it could not be confirmed whether this translated into clinical benefits. ${ }^{162}$ A selection of educational aids has been developed and are reviewed elsewhere. ${ }^{163}$ National Jewish Health has a Web site with videos on proper inhaler instruction. ${ }^{164}$

Melani and colleagues reported that the strongest associations with inhaler misuse were older age, lower education level, and lack of proper instruction. ${ }^{118}$ Even the most user-friendly devices require education and demonstration, and all patients should, as early as possible, be given proper instruction. There are situations where it may be more important, such as initiating therapy or when disease control is not being achieved.

In one study, health care providers watched tablet-based multimedia educational videos that demonstrated correct inhaler technique by a clinical pharmacist with teach-back from the patient before being re-evaluated. ${ }^{165}$ Correct inhaler technique was significantly increased among all health care professionals after the training, with the largest increase for the Respimat device; 32\% versus 93\% demonstrated the correct steps for usage before and after training, respectively. Takaku et al ${ }^{161}$ evaluated the number of instructions necessary to minimize errors in using pMDI, DPI, and SMI and concluded that, for every device, at least 3 instructions were required to achieve an error rate $<10 \%$.

\section{Proper Inhalation Techniques}

The pMDI is a commonly used device because of the many medications that can be delivered, as well as provider and patient familiarity. Instructions are shown in Table 3. Patients should be instructed to rinse their mouth after use, regardless of the medication, because all medications contribute to tooth decay, and ICS can cause thrush and dysphonia. ${ }^{166}$ Many of the inhaled drugs are not very water-soluble (lipophilic), so an alcohol-based mouthwash might remove more drug from the oropharyngeal cavity.

Some pMDIs are stored and dispensed in foil packages with desiccants to minimize exposure to moisture. Drug degradation occurs slowly, although this can occur more rapidly at high temperatures, so adherence to the expiration date is warranted. Storage of the pMDI where the mouthpiece is kept downward can decrease consistency of doses, and thus this is not recommended. Priming with new use or re-priming if not used for a specified time period is recommended to avoid incomplete doses. Most pMDIs now have dose counters, and in the United States this is the case for all devices except for one brand of albuterol (Proventil). Notably, more puffs can be actuated 
Table 3. Pressurized Metered Dose Inhaler Instructions

\section{Take the cap off.}

2. Determine if there are doses remaining in the inhaler.

3. Shake the inhaler multiple times prior to use.

4. Prime inhaler if it is new or has not been used in the last few days by spraying at least one actuation into the air.

5. Exhale slowly to empty the lungs.

6. Lean head back slightly.

7. Hold the inhaler in an upright position with the mouthpiece at bottom.

8. Place the inhaler in the mouth between the teeth, with the tongue flat under the mouthpiece. Close lips firmly around the mouthpiece.

9. At the same time as beginning a slow inhalation, press the canister to actuate a puff.

10. Maintain a slow and deep inhalation over $3-5 \mathrm{~s}$ until the lungs are full of air.

11. Continue to hold the breath for $5-10 \mathrm{~s}$ before breathing out.

12. Repeat second inhalation as above.

13. Rinse or otherwise clean mouth after each dose.

from the pMDI after the labeled number of maximum puffs is reached. However, drug delivery becomes variable and eventually minimal as largely only propellant is being released. Many patients use their albuterol pMDI until nothing comes out, eventually wondering why it is not working as well, which is not a good situation for a patient in respiratory distress.

Clogging of HFA pMDI albuterol actuators has been reported. pMDIs should be cleaned at least once a week by removing the metal canister, running warm water through the actuator, shaking the actuator to remove water, and then drying the device per manufacturer's instructions.

Common user errors with pMDIs include not shaking vigorously before each inhalation, failure to empty lungs prior to inhalation (eg, the breath mint technique, where the aerosol pours out of the mouth), failure to tilt head to the correct position, inhaling too fast (and thus not slowly and deeply over 3-5 s), and failure to hold the breath after inhalation for at least $5 \mathrm{~s}$. The patient can repeat the steps when they are ready, and do not have to wait any specific time. Occasionally, patients actuate 2 puffs into their mouth at the same time and then inhale, which is a waste of the first actuation.

After inserting the pMDI into the VHC, similar steps are followed as for the pMDI alone, except that the patient can wait $1-2 \mathrm{~s}$ to inhale the dose. For VHCs that have an audible warning for inhalation that is too fast, the patient should breathe in so slowly as to make little or no sound, then hold the breath for 5-10 s.

DPIs like Ellipta involve preparing the dose by moving the cover to the side to expose the mouthpiece, whereas for the Turbuhaler the bottom is turned and a cover is taken
Table 4. Dry Powder Inhaler Instructions

1. Lift or take the cap or cover off.

2. Follow the dose preparation instructions in the package insert.

a. Ellipta: Slide cover until clicks.

b. Diskus: Slide cover, put tab forward.

c. Handihaler and Breezhaler: Lift cover, then mouthpiece, insert capsule, press side button to puncture capsule.

d. Turbuhaler: Remove cover. Holding the inhaler upright, turn the base forward until it stops, and then turn it back to its original position.

3. Do not point mouthpiece downward once a dose has been prepared for inhalation because the dose may fall out.

4. Exhale slowly away from the mouthpiece to empty the lungs.

5. Place lips firmly around mouthpiece, with tongue under the mouthpiece.

6. Inhale forcefully through the mouth. Do not gradually build up the speed of inhalation.

7. Continue inhaling until the lungs are full.

8. At the end of the inhalation, take the inhaler out of the mouth and close lips.

9. Hold the breath for 5-10 s.

a. For the Handihaler, exhale and breathe in through the device a second time.

10. Rinse or otherwise clean mouth after each dose.

off. For the Handihaler and Breezhaler, a capsule is inserted and punctured (Table 4). The patient should ensure that his or her lips or fingers do not cover the air inlets on the DPI during inhalation. Common errors for DPIs include not keeping the device in the correct position while loading the dose (eg, Turbuhaler needs to be held vertically when loading a dose), failure to tilt the head to the correct position, not emptying the lungs before inhalation, insufficient inspiratory effort, and no breath-hold. Accidentally closing the mouthpiece of the Ellipta prior to inhalation causes the dose to be lost. ${ }^{155}$ Failure to achieve a forceful inspiratory flow is the most common error with DPIs, occurring in $26-29 \%$ of cases. ${ }^{118}$ Sulaiman et al ${ }^{44}$ reported that an inadequate inspiratory flow for a DPI was common among subjects with COPD recently discharged from the hospital. An inadequate inspiratory effort may be related to the patient's impaired respiratory function; alternatively, perhaps they just do not take a rapid deep breath for some reason.

The Respimat requires a slow, deep inhalation similar to that required by the pMDI (Table 5). Notably, for the Combivent Respimat, the full dose is 1 puff, whereas for the Striverdi, Stiolto, and Spiriva the dose is 2 puffs. While turning the base of the device to load a dose, 1 puff is wasted if it is turned past the click. Once the medication canister is inserted, it should not be removed as drug will be lost. Common errors are similar to those found with the pMDI, except that the slow, prolonged actuation allows for some patient error. 


\section{Aerosol Delivery Devices for Obstructive Lung Diseases}

Table 5. Soft Mist Inhaler Instructions

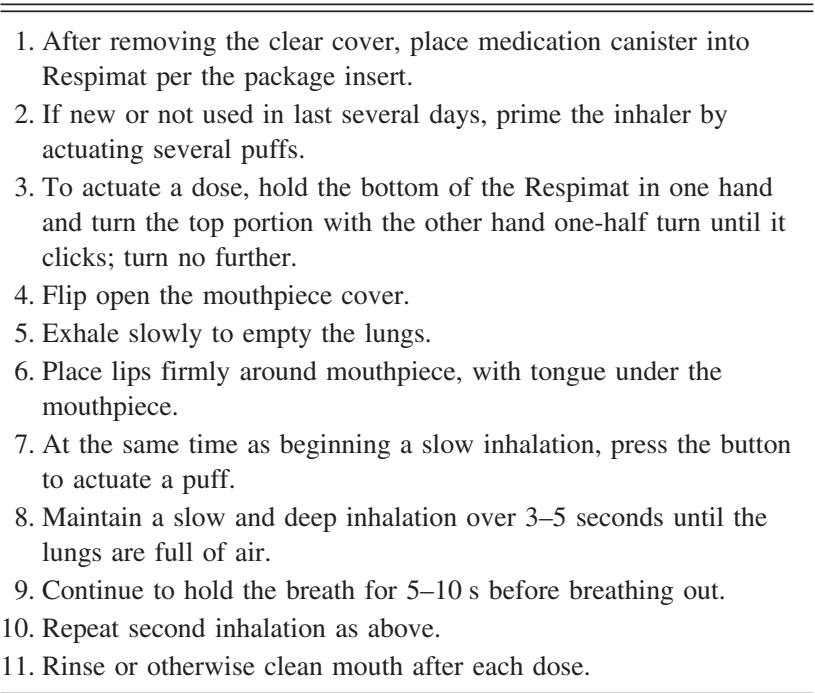

\section{Summary}

This review supplements published guidelines for aerosol delivery. $3,18,167$ Correct use of inhalation devices and adherence to prescribed therapy are key aspects to achieve better clinical control, improved quality of life, and fewer adverse effects. However, a wide range of factors are known to present challenges to patients with respect to inhaler use, including inhalation technique and pulmonary function. Using aerosol delivery devices correctly requires interaction between providers and patients to assure correct use and adherence. This responsibility is shared by physicians, respiratory therapists, pharmacists, nurses, and others involved in the care of the patient.

\section{REFERENCES}

1. Stein SW, Thiel CG. The history of therapeutic aerosols: a chronological review. J Aerosol Med Pulm Drug Deliv 2017;30(1): 20-41.

2. Sanchis J, Gich I, Pedersen S. Systematic review of errors in inhaler use. Has patient technique improved over time? Chest 2016;150(2): 394-406.

3. Laube BL, Janssens HM, de Jong FHC, Devadason FG, Dhand R, Everhard ML, et al. ERS/ISAM Task Force Report. What the pulmonologist should know about new inhalational therapies. Eur Respir J 2011;37(6):1308-1331.

4. Nahar K, Gupta N, Gauvin R, Absar S, Patel B, Gupta V, et al. In vitro, in vivo and ex vivo models for studying particle deposition and drug absorption of inhaled pharmaceuticals. Eur J Pharmaceutical Sci 2013;49(5):805-818

5. Corcoran TE. Imaging in aerosol medicine. Respir Care 2015;60(6): 850-857.

6. Thompson RB, Finlay WH. Using MRI to measure aerosol deposition. J Aerosol Med Pulmon Drug Deliv 2012;25(2):55-62.

7. Newman SP, Steed KP, Reader SJ. Efficient delivery to the lungs of flunisolide aerosol from a new portable hand-held multidose nebulizer. J Pharm Sci 1996;85(9):960-964.
8. Kirby M, Mathew L, Heydarian M, McCormack DG, Etemad-Rezai R, Parraga G. Chronic obstructive pulmonary disease: quantification of bronchodilator effects by using hyperpolarized $3 \mathrm{He}$ MR imaging. Radiology 2011;261(1):283-292.

9. Lipworth BJ. Pharmacokinetics of inhaled drugs. Br J Clin Pharmacol 1996;42(6):697-705.

10. Mortensen NP, Hickey AJ. Targeting inhaled therapy beyond the lungs. Respiration 2014;88(5):353-364.

11. Lavorini F, Pedersen S, Usmani OS. Dilemmas, confusion, and misconceptions: related to small airways directed therapy. Chest 2017;151(6):1345-1355.

12. Olsson B, Bondesson E, Bongstrom L, Edsbäcker S, Eirefelt S, Ekelund K, Gustavsson L, Hegelund-Myrbäck T. Pulmonary drug metabolism, clearance, and absorption. In: Controlled Pulmonary Drug Delivery, eds Smyth HDC, Hickey AJ. New York: Springer; 2011;21-50.

13. Kobrich R, Rudolf G, Stahlhofen W. A mathematical model of mass deposition in man. Ann Occup Hyg 1994;38(Suppl 1):15-23.

14. Labiris NR, Dolovich MB. Pulmonary drug delivery. Part I: physiological factors affecting therapeutic effectiveness of aerosolized medications. Br J Clin Pharmacol 2003;56(6):588-599.

15. Schamberger AC, Mise N, Jia J, Genoyer E, Yildirim AÖ, Meiners $\mathrm{S}$, Eickelberg O. Cigarette smoke-induced disruption of bronchial epithelial tight junctions is prevented by transforming growth factor- $\beta$. Am J Respir Cell Mol Biol 2014;50(6):1040-1052.

16. Roberts JK, Moore CD, Ward RM, Yost GM, Reilly CA. Metabolism of beclomethasone dipropionate by cytochrome P450 3A enzymes. J Pharmacol Exp Ther 2013;345(2):308-316.

17. Hess DR. Aerosol delivery devices in the treatment of asthma. Respir Care 2008;53(6):699-723.

18. Dolovich MB, Ahrens RC, Hess DR, Anderson P, Dhand R, Ray JL, et al. Device selection and outcomes of aerosol therapy: evidence-based guidelines. Chest 2005;127(1):335-371.

19. Newman SP. Principles of metered-dose inhaler design. Respir Care 2005;50(9):1177-1190.

20. Hou S, Wu J, Li X, Shu H. Practical, regulatory and clinical considerations for development of inhalation drug products. Asian J Pharm Sci 2015;10(8):490-500.

21. Ferguson G, Hickey AJ, Dwivedi S. Co-suspension delivery technology in pressurized metered-dose inhalers for multi-drug dosing in the treatment of respiratory diseases. Respir Med 2018;134: 16-23.

22. Dalby RN, Eicher J, Zierneberg B. Development of Respimat Soft Mist inhaler and its clinical utility in respiratory disorders. Med Devices (Auckl) 2011;4:145-55.

23. Pitcairn G, Reader S, Pavia D, Newman S. Deposition of corticosteroid aerosol in the human lung by Respimat Soft Mist inhaler compared with deposition by metered dose inhaler or by Turbuhaler dry powder inhaler. J Aerosol Med 2005;18(3):264-272.

24. Anderson P. Use of Respimat Soft Mist inhaler in COPD patients. Int J Chron Obstruct Pulmon Dis 2006;1(3):251-259.

25. Spiriva Respimat Product Insert. Boehringer Ingelheim: Connnecticut; 2017.

26. Newman SP, and Newhouse MT. Effect of add-on devices for aerosol drug delivery: deposition studies and clinical aspects. J Aerosol Med 1996;9(1):55-70.

27. Dissanayake S, Suggett J. A review of the in vitro and in vivo valved holding chamber (VHC) literature with a focus on the AeroChamber Plus Flow-Vu Anti-static VHC. Ther Adv Respir Dis 2018;12:1-14.

28. Clark DJ, Lipworth BJ. Effect of multiple actuations, delayed inhalation and antistatic treatment on the lung bioavailability of salbutamol via a spacer device. Thorax 1996;51(10):981-984. 


\section{Aerosol Delivery Devices for Obstructive Lung Diseases}

29. Slator L, von Hollen D, Sandell D, Hatley RHM. In vitro comparison of the effect of inhalation delay and flow rate on the emitted dose from three valved holding chambers. J Aerosol Med Pulmon Drug Deliv 2014;27(Suppl 1):S37-S43.

30. Leach CL, Colice GL. A pilot study to assess lung deposition of HFA-beclomethasone and CFC-beclomethasone from a pressurized metered dose inhaler with and without add-on spacers and using varying breathhold times. J Aerosol Pulm Drug Deliv 2010;23(6): 355-361.

31. Singh D, Collarini S, Poli G, Acerbi D, Amadasi A, Rusca A. Effect of AeroChamber Plus on the lung and systemic bioavailability of beclomethasone dipropionate/formoterol pMDI. Br J Clin Pharmacol 2011;72(6):932-939.

32. Anhoj J, Bisgaard H, Lipworth BJ. Effect of electrostatic charge in plastic spacers on the lung delivery of HFA-salbutamol in children. Br J Clin Pharmacol 1999;47(3):333-336.

33. Wildhaber JH, Waterer GW, Hall GL, Summers QA. Reducing electrostatic charge on spacer devices and bronchodilator response. Br J Clin Pharmacol 2000;50(3):277-280.

34. Dal Nagro RW. Dry powder inhalers and the right things to remember: a concept review Multidisc Respir Med 2015;10(1):13.

35. Mahler DA, Peak inspiratory flow rate as a criterion for dry powder inhaler use in chronic obstructive pulmonary disease. Ann Amer Thorac Soc 2017;14(7):1103-1107.

36. Ghosh S, Ohar JA, Drummond MB. Peak inspiratory flow rate in chronic obstructive pulmonary disease: implications for dry powder inhalers. J Aerosol Med Pulm Drug Deliv 2017;30(6):1-7.

37. Kikidis D, Konstantinos V, Tzovaras D, Usmani OS. The digital asthma patient: the history and future of inhaler-based health monitoring devices. J Aerosol Med Pulmon Drug Deliv 2016;29(3):219232.

38. Carpenter DM, Roberts CA, Sage AJ, George J, Horne R. A review of electronic devices to assess inhaler technique. Curr Allergy Asthma Rep 2017;17(3):17.

39. Kim MS, Henderson KA, Sickle DV. Using connected devices to monitor inhaler use in the real world. Respir Drug Deliv 2016;1: 37-44.

40. Fan VS, Gyly-Colwell I, Locke E, Sumino K, Ngyyen HQ, Thomas RM, Magzame S. Overuse of short-acting beta-agonist bronchodilators in COPD during periods of clinical stability. Respir Med 2016;116(7):100-106.

41. Merchant RK, Inamdar R, Quade RC. Effectiveness of population health management using the propeller health asthma platform: a randomized clinical trial. J Allergy Clin Immunol Pract 2016;4(3): 455-463.

42. Seheult JN, Costello S, Tee KC, et al. Investigating the relationship between peak inspiratory flow rate and volume of inhalation from a Diskus Inhaler and baseline spirometric parameters: a cross-sectional study. Springerplus 2014;2(3):496.

43. Seheult JN, O'Connell P, Tee KC, Bholah T, Al Bannai H, Sulaiman I, et al. The acoustic features of inhalation can be used to quantify aerosol delivery from a Diskus dry powder inhaler. Pharm Res 2014;31:2735-2747.

44. Sulaiman I, Seheult J, Sadasivuni N, Bholah T, Al Bannai H, Sulaiman I, et al. The impact of common inhaler errors on drug delivery: investigating critical errors with a dry powder inhaler. J Aerosol Med Pulm Drug Deliv 2017;30(10):247-255.

45. Sulaiman I, Cushan B, Greene G, Seheult J, Seow D, Rawat F, et al. Objective assessment of adherence to inhalers by patients with chronic obstructive pulmonary disease. Am J Respir Crit Care Med 2017;195(10):1333-1343.

46. Sulaiman I, Greene G, MacHale E, Seheult J, Mokoka M, D’Arcy $\mathrm{SD}$, et al. A randomised clinical trial of feedback on inhaler adher- ence and technique in patients with severe uncontrolled asthma. Eur Respir J 2018;51(1):1701126.

47. Everhard ML, Evans M, Milner AD. Is tapping jet nebulizers worthwhile? Arch Dis Child 1994;70(6):538-539.

48. Malone RA, Hollie MC, Glynn-Barnhart A, Nelson HS. Optimal duration of nebulized albuterol therapy. Chest 1993;104(4):11141118.

49. Hess D, Fisher D, Williams P, Pooler S, Kacmarek RM. Medication nebulizer performance. Effects of diluent volume, nebulizer flow, and nebulizer brand. Chest 1996;110(2):498-505.

50. Terzano C, Petroianni A, Parola D, Ricci A. Compressor/nebulizers differences in the nebulization of corticosteroids. The CODE study (Corticosteroids and Devices Efficiency). Eur Rev Med Pharmacol Sci 2007;11(4):225-237.

51. Waldrep JC, Keyhani K, Black M, Knight V. Operating characteristics of 18 different continuous-flow jet nebulizers with beclomethasone dipropionate liposome aerosol. Chest 1994;105(1):106110.

52. Awad SW, Berlinski A. Crossover evaluation of compressors and nebulizers typically used by cystic fibrosis patients. Respir Care 2018;63 (3) 294-300.

53. Awad S, Williams DK, Berlinski A. Longitudinal evaluation of compressor/nebulizer performance. Respir Care 2014;59(7):10531061.

54. Reisner C, Katial RK, Bartelson BB, Buchmeir A, Rosenwasser LJ, Nelson HS. Characterization of aerosol output from various nebulizer/compressor combinations. Ann Allergy Asthma Immunol 2001; 86(5):566-574.

55. Standaert TA, Bohn SE, Aitken ML, Ramsey B. The equivalence of compressor pressure-flow relationships with respect to jet nebulizer aerosolization characteristics. J Aerosol Med 2001;14(1):31-42.

56. Everard ML, Hardy JG, Milner AD. Comparison of nebulized aerosol deposition in the lungs of healthy adults following oral and nasal inhalation. Thorax 1993;48(10):1045-1046.

57. Nikander K, Agertoft L, Pedersen S. Breath-synchronized nebulization diminishes the impact of patient-device interfaces (face mask or mouthpiece) on the inhaled mass of nebulized budesonide. J Asthma 2000;37(5):451-459.

58. Kishida M, Suzuki I, Kabayama H, Koshibu T, Izawa M, Takeshita $\mathrm{Y}$, et al. Mouthpiece versus facemask for delivery of nebulized salbutamol in exacerbated childhood asthma. J Asthma 2002;39(4): 337-339.

59. Kohler E, Sollich V, Schuster-Wonka R, Huhnerbein J, Jorch G. Does wearing a noseclip during inhalation improve lung deposition? J Aerosol Med 2004;17(2):116-122.

60. Meier R, Hall GL, Sennhauser FH, Wildhaber JH. Wearing a noseclip improves nebulised aerosol delivery. Swiss Med Wkly 2001; 131(33-34):495-497.

61. Bisquerra RA, Botz GH, Nates JL. Ipratropium-bromide-induced acute anisocoria in the intensive care setting due to ill-fitting face masks. Respir Care 2005;50(12):1662-1664.

62. Brodie T, Adalat S. Unilateral fixed dilated pupil in a well child. Arch Dis Child 2006;91(12):961.

63. Erzinger S, Schueepp KG, Brooks-Wildhaber J, Devadason SG, Wildhaber JH. Facemasks and aerosol delivery in vivo. J Aerosol Med 2007;20(Suppl 1):S78-S84.

64. Hayden JT, Smith N, Woolf DA, Barry PW, O'Callaghan C. A randomised crossover trial of facemask efficacy. Arch Dis Child 2004;89(1):72-73.

65. Sangwan S, Gurses BK, Smaldone GC. Facemasks and facial deposition of aerosols. Pediatr Pulmonol 2004;37(5):447-452.

66. Smaldone GC, Sangwan S, Shah A. Facemask design, facial deposition, and delivered dose of nebulized aerosols. J Aerosol Med 2007;20(Suppl 1):S66-S77. 


\section{Aerosol Delivery Devices for Obstructive Lung Diseases}

67. Janssens HM, Tiddens HA. Aerosol therapy: the special needs of young children. Paediatr Respir Rev 2006;7(Suppl 1):S83-S85.

68. Rubin BK. Bye-bye, blow-by. Respir Care 2007;52(8):981.

69. Pisut FM. Comparison of medication delivery by T-nebulizer with inspiratory and expiratory reservoirs. Respir Care 1989;34(11):985988.

70. Pitance L, Reychler G, Leal T, Reychler H, Liistro G, Montharu J, et al. Aerosol delivery to the lung is more efficient using an extension with a standard jet nebulizer than an open-vent jet nebulizer. J Aerosol Med Pulm Drug Deliv 2013;26(4):208-214.

71. Corcoran TE, Dauber JH, Chigier N, Iacono AT. Improving drug delivery from medical nebulizers: the effects of increased nebulizer flow rates and reservoirs. J Aerosol Med 2002;15(3):271-282.

72. Hoffman L, Smithline H. Comparison of Circulaire to conventional small volume nebulizer for the treatment of bronchospasm in the emergency department. Respir Care 1997;42(12):1170-1174.

73. Mason JW, Miller WC. Comparison of aerosol delivery via circulaire nebulizer system versus a disposable nebulizer in COPD patients. Respir Care 1996;41(11):1006-1008.

74. Mason JW, Miller WC, Small S. Comparison of aerosol delivery via circulaire system vs conventional small volume nebulizer. Respir Care 1994;39(12):1157-1161.

75. Piper SD. In vitro comparison of the Circulaire and AeroTee to a traditional nebulizer T-piece with corrugated tubing. Respir Care 2000;45(3):313-319.

76. Rau JL, Ari A, Restrepo RD. Performance comparison of nebulizer designs: constant-output, breath-enhanced, and dosimetric. Respir Care 2004;49(2):174-179.

77. Devadason SG, Everard M, Linto JM, Le Souef PN. Comparison of drug delivery from conventional versus "Venturi" nebulizers. Eur Respir J 1997;10(11):2497-2483.

78. Ho SL, Kwong WT, O'Drowsky L, Coates AL. Evaluation of four breath-enhanced nebulizers for home use. J Aerosol Med 2001; 14(4):467-475

79. Lin HL, Fang TP, Cho HS, Wan GH, Hsieh MJ, Fink JB. Aerosol delivery during spontaneous breathing with different types of nebulizers-in vitro/ex vivo models evaluation. Pulm Pharmacol Ther 2018;48(2):225-231.

80. Leung K, Louca E, Coates AL. Comparison of breath-enhanced to breath-actuated nebulizers for rate, consistency, and efficiency. Chest 2004;126(5):1619-1627.

81. Newman SP, Pitcairn GR, Hooper G, Knoch M. Efficient drug delivery to the lungs from a continuously operated open-vent nebulizer and a low pressure compressor system. Eur Respir J 1994; 7(6):1177-1181.

82. Newnham DM, Lipworth BJ. Nebulizer performance, pharmacokinetics, airways and systemic effects of salbutamol given via a novel nebuliser system (Venstream). Thorax 1994;49(8):762-770.

83. Rau JL. Design principles of liquid nebulization devices currently in use. Respir Care 2002;47(11):1257-1275.

84. Nikander K, Bisgaard H. Impact of constant and breath-synchronized nebulization on inhaled mass of nebulized budesonide in infants and children. Pediatr Pulmonol 1999;28(3):187-193.

85. Nikander K, Turpeinen M, Wollmer P. Evaluation of pulsed and breath-synchronized nebulization of budesonide as a means of reducing nebulizer wastage of drug. Pediatr Pulmonol 2000;29(2): 120-126.

86. Arunthari V, Bruinsma RS, Lee AS, Johnson MM. A prospective, comparative trial of standard and breath-actuated nebulizer: efficacy, safety, and satisfaction. Respir Care 2012;57(8):1242-1247.

87. Sabato K, Ward P, Hawk W, Gildengorin V, Asselin JM. Randomized controlled trial of a breath-actuated nebulizer in pediatric asthma patients in the emergency department. Respir Care 2011;56(6):761-770.
88. Dhand R. Nebulizers that use a vibrating mesh or plate with multiple apertures to generate aerosol. Respir Care 2002;47(12):14061416.

89. Lass JS, Sant A, Knoch M. New advances in aerosolised drug delivery: vibrating membrane nebuliser technology. Expert Opin Drug Deliv 2006;3(5):693-702.

90. Knoch M, Keller M. The customised electronic nebuliser: a new category of liquid aerosol drug delivery systems. Expert Opin Drug Deliv 2005;2(2):377-390.

91. Ari A. Aerosol therapy in pulmonary critical care. Respir Care 2015;60(6):858-874.

92. Gowda AA, Cuccia AD, Smaldone GC. Reliability of vibrating mesh technology. Respir Care 2017;62(1):65-69.

93. Pitance L, Vecellio L, Leal T, Reychler G, Reychler H, Liistro G. Delivery efficacy of a vibrating mesh nebulizer and a jet nebulizer under different configurations. J Aerosol Med Pulm Drug Deliv 2010;23(6):389-396.

94. Ari A, de Andrade AD, Sheard M, AlHamad B, Fink JB. Performance comparisons of jet and mesh nebulizers using different interfaces in simulated spontaneously breathing adults and children. J Aerosol Med Pulm Drug Deliv 2015;28(4):281-289.

95. Hill NS, Preston IR, Roberts KE. Inhaled therapies for pulmonary hypertension. Respir Care 2015;60(6):794-802.

96. Nikander K, Turpeinen M, Wollmer P. The conventional ultrasonic nebulizer proved inefficient in nebulizing a suspension. J Aerosol Med 1999;12(2):47-53.

97. Singh S, Kanbar-Agha F, Sharafkhaneh A. Novel aerosol delivery devices. Semin Respir Crit Care Med 2015;36(4):543-551.

98. Zhou QT, Tang P, Leung SS, Chan JG, Chan HK. Emerging inhalation aerosol devices and strategies: where are we headed? Adv Drug Deliv Rev 2014;75:3-17.

99. Denyer J, Dyche T. The adaptive aerosol delivery (AAD) technology: past, present, and future. J Aerosol Med Pulm Drug Deliv 2010;23(Suppl 1):S1-S10.

100. Byrne NM, Keavey PM, Perry JD, Gould FK, Spencer DA. Comparison of lung deposition of colomycin using the HaloLite and the Pari LC Plus nebulisers in patients with cystic fibrosis. Arch Dis Child 2003;88(8):715-718.

101. Denyer J, Nikander K, Smith NJ. Adaptive aerosol delivery (AAD) technology. Expert Opin Drug Deliv 2004;1(1):165-176.

102. Nikander K, Arheden L, Denyer J, Cobos N. Parents' adherence with nebulizer treatment of their children when using an adaptive aerosol delivery (AAD) system. J Aerosol Med 2003;16(3):273281.

103. Van Dyke RE, Nikander K. Delivery of iloprost inhalation solution with the HaloLite, Prodose, and I-neb Adaptive Aerosol Delivery systems: an in vitro study. Respir Care 2007;52(2):184-190.

104. Peters SG. Continuous bronchodilator therapy. Chest 2007;131(1): 286-289.

105. Salo D, Tuel M, Lavery RF, Reischel U, Lebowitz J, Moore T. A randomized, clinical trial comparing the efficacy of continuous nebulized albuterol $(15 \mathrm{mg}$ ) versus continuous nebulized albuterol (15 $\mathrm{mg})$ plus ipratropium bromide $(2 \mathrm{mg})$ for the treatment of acute asthma. J Emerg Med 2006;31(4):371-376.

106. Camargo CA Jr, Spooner CH, Rowe BH. Continuous versus intermittent beta-agonists in the treatment of acute asthma. Cochrane Database Syst Rev 2003(4):CD001115.

107. Hess DR, Fink JB, Venkataraman ST, Kim IK, Myers TR, Tano BD. The history and physics of heliox. Respir Care 2006;51(6): 608-612.

108. Rodrigo GJ, Castro-Rodriguez JA. Heliox-driven beta2-agonists nebulization for children and adults with acute asthma: a systematic review with meta-analysis. Ann Allergy Asthma Immunol 2014; 112(1):29-34. 


\section{Aerosol Delivery Devices for Obstructive Lung Diseases}

109. Hess DR, Acosta FL, Ritz RH, Kacmarek RM, Camargo CA, Jr. The effect of heliox on nebulizer function using a beta-agonist bronchodilator. Chest 1999;115(1):184-189.

110. Corcoran TE, Gamard S. Development of aerosol drug delivery with helium oxygen gas mixtures. J Aerosol Med 2004;17(4):299309.

111. O'Callaghan C, White J, Jackson J, Crosby D, Dougill B, Bland H. The effects of heliox on the output and particle-size distribution of salbutamol using jet and vibrating mesh nebulizers. J Aerosol Med 2007;20(4):434-444.

112. Burchett DK, Darko W, Zahra J, Noviasky J, Probst L, Smith A. Mixing and compatibility guide for commonly used aerosolized medications. Am J Health Syst Pharm 2010;67(3):227-230.

113. Ari A, Fink JB, Dhand R. Inhalation therapy in patients receiving mechanical ventilation: an update. J Aerosol Med Pulm Drug Deliv 2012;25(6):319-332.

114. Dhand R. How should aerosols be delivered during invasive mechanical ventilation? Respir Care 2017;62(10):1343-1367.

115. Hess DR. Aerosol therapy during noninvasive ventilation or highflow nasal cannula. Respir Care 2015;60(6):880-891.

116. Berlinski A, Ari A, Davies P, Fink J, Majaesic C, Reychler G, et al. Workshop report: aerosol delivery to spontaneously breathing tracheostomized patients. J Aerosol Med Pulm Drug Deliv 2017;30(4): 207-222.

117. Standaert TA, Morlin GL, Williams-Warren J, Joy P, Pepe MS, Weber A, et al. Effects of repetitive use and cleaning techniques of disposable jet nebulizers on aerosol generation. Chest 1998;114(2): 577-586

118. Melani AS, Bonavia M, Cilenti V, Cinti C, Lodi M, Martucci P, et al. Inhaler mishandling remains common in real life and is associated with reduced disease control. Respir Med 2011;105(6):930-938.

119. Mahler DA, Waterman LA, Ward J, Gifford AH. Comparison of dry powder versus nebulized beta-agonist in patients with COPD who have suboptimal peak inspiratory flow rate. J Aerosol Med Pulm Drug Deliv 2014;27(2):103-109.

120. Price D, Roche N, Virchow JC. Device type and real-world effectiveness of asthma combination therapy: an observational study. Respir Med 2011;105:1457-1466.

121. Jones R, Martin J, Thomas V, Skinner D, Marshall J, Slagno D, et al. The comparative effectiveness of initiating fluticasone/salmeterol combination therapy via pMDI versus DPI in reducing exacerbations and treatment escalation in COPD: a UK database study. Int J Chron Obstruct Pulmon Dis 2017;12;2445-2454.

122. Dekhuijzen PNR, Batsiou M, Bjermer L, Bosnic-Anticevich S, Chrystyn H, Papi A, et al. Incidence of oral thrush in patients with COPD prescribed inhaled corticosteroids : effect of drug, dose, and device. Respir Med 2016;120:54-63.

123. Goldin JG, Tashkin DP, Kleerup EC, Greaser LE, Haywood UM, et al. Comparative effects of hydrofluoroalkane and chlorofluorocarbon beclomethasone dipropionate inhalation on small airways: Assessment with functional helical thin section computed tomography. J Aller Clin Immunol 1999;104(6):S258-S267.

124. Nielsen KG, Bojsen AK, Iversen M, Ifversen M, Klug B, Bisgaard H. Clinical effect of Diskus dry-powder inhaler at low and high inspiratory flow-rates in asthmatic children. Eur Respir J 1998; 11(2):350-354

125. Loh CH, Peters SP, Lovings TM, Ohar JA. Suboptimal inspiratory flow rates are associated with chronic obstructive pulmonary disease and all cause readmissions. Ann Am Thorac Soc 2017;14(8): 1305-1311

126. Sharma G, Mayorga VM, Deering KL, Harshaw Q, Ganapathy V. Prevalence of low peak inspiratory flow rate at discharge in patients hospitalized for COPD exacerbation. J COPD Found 2017;4(3): 217-224.
127. Stevenson NJ, Walker PP, Costello RW, Calverley PMA. Lung mechanics and dyspnea during exacerbations of chronic obstructive pulmonary disease. Am J Respir Crit Care Med 2005;172(12):1510-1516.

128. Broeders ME, Molema J, Hop WC, Vermue NA, Folgering HT. The course of inhalation profiles during an exacerbation of obstructive lung disease. Respir Med 2004;98(12):1173-1179.

129. Bateman ED, Linnhof AE, Homik L, Freudensprung U, Smau L Engelstätter R. Comparison of twice-daily inhaled ciclesonide and fluticasone propionate in patients with moderate-to-severe persistent asthma. Pulm Pharmacol Ther 2008;21(2):264-275.

130. Derom E, Van De Velde V, Marissens S, Engelstätter R, Vincken W, Pauwels R. Effects of inhaled ciclesonide and fluticasone propionate on cortisol secretion and airway responsiveness to adenosine 5 'monophosphate in asthmatic patients. Pulm Pharmacol Ther 2005;18(5):328-336.

131. Derom E, Louis R, Tiesler C, Engelstätter R, Kaufman JM, Joos GF. Effects of ciclesonide and fluticasone on cortisol secretion in patients with persistent asthma. Eur Respir J 2009;33(6):1277-1286.

132. Hoshino M. Comparison of effectiveness in ciclesonide and fluticasone propionate on small airway function in mild asthma. Allergol Int 2010;59(1):59-66.

133. Huchon G, Magnussen H, Chuchalin A, Dymek L, Gonod FB, Bousquet $\mathrm{J}$, et al. Lung function and asthma control with beclomethasone and formoterol in a single inhaler. Respir Med 2009; 103(1):41-49.

134. Papi A, Paggiaro P, Nicolini G, Vignola AM, Fabbri LM, the ICAT SE study group. Beclomethasone/formoterol vs fluticasone/salmeterol inhaled combination in moderate to severe asthma. Allergy 2007;62(10):1182-1188.

135. Postma DS, Roche N, Colice G, Israel E, Martin RJ, van Aalderen WM, et al. Comparing the effectiveness of small-particle versus large-particle inhaled corticosteroid in COPD. Int J Chron Obstruct Pulmon Dis 2014;9:1163-1186.

136. Usmani OS, Biddiscombe MF, Barnes PJ. Regional lung deposition and bronchodilator response as a function of beta $a_{2}$-agonist particle size. Am J Respir Crit Care Med 2005;172(12):1497-1504.

137. Zanen P, Go LT, Lammers JW. Optimal particle size for beta 2agonist and anticholinergic aerosols in patients with severe airflow obstruction. Thorax 1996;51(10):977-980.

138. Small M, Anderson P, Vickers A, Kay S, Fermer S. Importance of inhaler-device satisfaction in asthma treatment: real-world observations of physician-observed compliance and clinical/patient-reported outcomes. Adv Ther 2011;28(3):202-212.

139. Malmberg LP, Rytila P, Happonen P, and Haahtela T. Inspiratory flows through dry powder inhaler in chronic obstructive pulmonary disease: age and gender rather than severity matters. Int J Chron Obstruct Pulmon Dis 2010;5:257-262.

140. Feddah MR, Brown KR, Gipps, Davies NM. In vitro characterization of metered dose inhaler versus dry powder inhaler glucocorticoid products: influence of inspiratory flow rates. J Pharm Pharmaceut Sci 2000;3(3):318-324

141. Yokohama H, Yamamura Y, Oseki T. Analysis of relationship between peak inspiratory flow rate and amount of drug delivered to lungs following inhalation of fluticasone propionate with a Diskhaler. Biol Pharm Bull 2007;30(1):162-164.

142. Grant AC, Walker R, Hamilton M, Garrill K. The ELLIPTA dry powder inhaler: design, functionality, in vitro dosing performance and critical task compliance by patients and caregivers. J Aerosol Med Pulm Drug Deliv 2015;28(6):1-12.

143. Prime D, de Backer W, Hamilton M, Cahn A, Preece A, Kelleher $\mathrm{D}$, et al. Effect of disease severity in asthma and chronic obstructive pulmonary disease on inhaler-specific Inhalation profiles through the Ellipta dry powder inhaler. J Aerosol Med Pulm Drug Deliv 2015;28(6):486-497. 


\section{Aerosol Delivery Devices for Obstructive Lung Diseases}

144. Buttini F, Brambilla G, Copella D, et al. Effect of flow rate on in vitro aerodynamic performance of NEXThaler in comparison with Diskus and Turbohaler dry powder inhalers. J Aerosol Med Pulm Drug Deliv 2016;29(2):167-178.

145. Hamilton M, Leggett R, Pang C, Charles S, Gillett BD. In vitro dosing performance of the ELLIPTA dry powder inhaler using asthma and COPD patient inhalation profiles replicated with the Electronic Lung (eLungTM). J Aerosol Med Pulm Drug Deliv 2015(6):28:1-9.

146. Mahler DA, Waterman LA, Gifford AH. Prevalence and COPD phenotype for a suboptimal peak inspiratory flow rate against the simulated resistance of the Diskus dry powder inhaler. J Aerosol Med Pulm Drug Deliv 2013;26(3):174-179.

147. Janssens W, VandenBrande $P$, Hardeman E, De Langhe E, Philps $\mathrm{T}$, Troosters T, Decramer M, et al. Inspiratory flow rates at different levels of resistance in elderly COPD patients. Eur Respir J 2008; 31(1):78-83

148. Jordanaglou J, Pride NB. A comparison of maximum inspiratory and expiratory flow in health and in lung disease. Thorax 1968; 23(1):38.

149. Wade OL, Gilson JC. The effect of posture on diaphragmatic movement and vital capacity in normal subjects with a note on spirometry as an aid in determining radiological chest volumes. Thorax 1951;6(2):103.

150. Taube C, Rydzy L, Eich A, Corn S, Kommann S, Sebastian M, et al. Use of a portable device to record maximum inspiratory flow in relation to dyspnoea in patients with COPD. Respir Med 2011; 105:316-321.

151. Sa RC, Zeman KL, Bennett WD, Prisk GK, Darquenne C. Effect of posture on regional deposition of coarse particles in the healthy human lung. J Aerosol Pulm Drug Deliv 2014;28(6):423-431.

152. Pleasants RA. Dry powder inhalers and humidity: another factor to consider to ensure adequate lung delivery. Ann Am Thorac Soc 2017;14(10): 1602

153. Borgstrom L, Asking L, Lipiniuas P. An in vivo and in vitro comparison of two powder inhalers following storage at hot/humid conditions. J Aerosol Med 2005;18(3):304-310.

154. Janson C, Loof T, Telg G, Stratelis G, Nilsson F. Difference in resistance to humidity between commonly used dry powder inhalers: an in vitro study. Prim Care Respir Med 2016;26:16053.

155. Breo Ellipta package insert. Research Triangle Park, NC: GlaxoSmithKline.
156. Seretide Accuhaler package insert. Hertfordshire, UK: GlaxoSmithKline.

157. Spiriva Handihaler package insert. Ridgefield, CT: Boehringer Ingelheim Pharmaceuticals, Inc.

158. Normansell R, Kew KM, Mathioudakis AG. Interventions to improve inhaler technique for people with asthma. Cochrane Database Syst Rev 2017;3:CD012286.

159. Goodwin R, Chander T, Shah N, Tomlin S. Inhaler counselling, the real deal or just fresh air? Arch Dis Child 2016;101(9):e2.

160. Bosnic-Anticevich SZ, Sinha H, So S, Reddel HK. Metered-dose inhaler technique: the effect of two educational interventions delivered in community pharmacy over time. J Asthma 2010;47(3): 251-256.

161. Takaku Y, Kurashima K, Ohta C, Ishiguro T, Kagiyama N, Yanagisawa $\mathrm{T}$, Takayanagi $\mathrm{N}$. How many instructions are required to correct inhalation errors in patients with asthma and chronic obstructive pulmonary disease? Respir Med 2017;123(2): 110-115.

162. Chrystyn H, van der Palen J Sharma R, Barnes N, Delafont B, et al. Device errors in asthma and COPD: systematic literature review and meta-analysis. NPJ Primary Care Respir Med 2017; 27(1):22.

163. Lavorini F, Levy ML, Corrigan C, Crompton G, ADMIT Working Group. The ADMIT series - issues in inhalation therapy. 6) Training tools for inhalation devices. Prim Care Respir J 2010;19(4): 335-341.

164. National Jewish Health. Instructional videos. Available at: https:// www.nationaljewish.org/treatment-programs/medications/asthmamedications/devices/instructional-videos. Accessed May 2, 2018.

165. Mulhall AM, Zafar MA, Record S, Channell H, Panos RJ. A tabletbased multimedia education tool improves provider and subject knowledge of inhaler use techniques. Respir Care 2017;62(2):163-171.

166. Godara N, Godara R, Khullar M. Impact of inhalation therapy on oral health. Lung India 2011;28(4):272-275.

167. Gardenhire DS, Burnett D, Strickland S, Myers TR. A Guide to Aerosol Delivery Devices for Respiratory Therapists, 4th ed. Irving, Texas: American Association for Respiratory Care; 2017.

168. Hess DR, Myers TR, Rau JL. A guide to aerosol delivery devices for respiratory therapists. Irving, Texas: American Association for Respiratory Care; 2005.

\section{Discussion}

MacIntyre: This is a topic we've had entire Journal Conferences ${ }^{1-4}$ on so we won't be able to summarize it here in 45 minutes, but let me just ask one question. We touched on this earlier, one of the putative advantages of a jet nebulizer, or any neb for that matter, is that you can put so much medicine in the neb that in fact the need to do a very careful inspiratory maneuvers, slow, fast, breath holds, no breath holds becomes less of an issue. Is it fair to say that the nebulizer is (and I hate to say this) idiot-proof and just overwhelms the system with more drug regardless of how bad your maneuvers are?

Pleasants: My opinion is, and we have some experts here who can speak on that, I think it can make a difference. We're giving much higher doses in these devices. Whether it really makes a difference in a research setting, I'm not sure that it does.

MacIntyre: I'm thinking in terms of the acute asthmatic. Michael [Newhouse], I know you're going to tell me that if I just used a spacer it would all work.
*Newhouse: No, what I am going to tell you is that in my opinion, for treating reversible airflow obstruction, nebulizers are obsolete.

MacIntyre: Let me just clarify that This may be my ignorance, but to use a pMDI or a DPI requires more cooperation on the part of the patient than does a nebulizer. If you put a nebulizer on someone all they have to do is breathe, is that fair to say?

*Newhouse: Not necessarily, it depends on whether they are willing to keep a mask on. 
MacIntyre: Well, of course.

*Newhouse: But very often they don't, and that's especially true of children.

Rubin: Neil [MacIntyre], the issue is you're talking about acute therapy. Somebody who's home with a nebulizer should be adherent but the adherence is less. You have to schlep it out, measure the medication into the cup, sit there and breathe for 5 minutes, then clean up after. If you give patients the impression that this is the device that works-you're sick now and this is what works-you may discourage them from using the other devices. I wouldn't say they're obsolete, but there are other reasons why you would consider using a different device instead of a nebulizer.

MacIntyre: Bruce, those are fair points and I totally agree with you. It's sort of a bias of where you practice and I practice in an ICU. And I have yet to see an ICU patient with acute airway obstruction able to effectively use either DPIs or pMDIs.

*Newhouse: That's exactly what's used virtually throughout the world. And is what the guidelines suggest.

MacIntyre: Michael, when was the last time you were in the ICU trying to treat a tight asthmatic with a spacer and a pMDI?

*Newhouse: I don't have to be, I read the literature. The literature and the guidelines say that that is what you should start with because it works very well and it's done very quickly. The patient gets better faster and is sent home more often and not admitted to the hospital. There are all sorts of reasons why you might want to take that approach.

Strange: I'll step into the debate. One thing to consider here is the dose.
When you calculate the $2.5 \mathrm{mg}$ albuterol dose in a nebulizer, the equivalent dose is 28 puffs from a pMDI.

MacIntyre: Charlie, that's exactly my point, with a nebulizer you overcome the reduction in dose delivery from tidal breathing by simply adding more medication. You do not need to rely on difficult to do maneuvers.

*Newhouse: The equivalent dose is not 28 puffs.

Strange: It is on a mg basis.

*Newhouse: The equivalent dose is less than half that. Most acute episodes, and again the literature is replete with this, take 10-12 puffs and they can be administered at 15 -s intervals so in and 4-5 min you can administer what you need instead of putting people on a small-volume nebulizer and giving it to them for $20 \mathrm{~min}$ and most of it is raindrops.

Strange: Let me just clarify this is the biologically equivalent dose vs the mg dose we're talking about.

*Newhouse: Yes, I'm talking about the dose response, the biologically effective dose.

MacIntyre: We probably need to move on but I'll stand by my statement that I have yet to see a tight asthmatic in an ICU who can slowly inhale a pMDI, hold their breath for a period of time, and take a near-vital capacity maneuver.

*Newhouse: They don't need to do it slowly. They tidal breathe and it isn't a problem. They have a mask on and do it in a very short time.

MacIntyre: OK, we agree to disagree here.

$\dagger$ Hess: I think the other thing we need to recognize is that not all for- mulations are available to be used in a DPI or pMDI. Outside the world of bronchodilators, I think there are a number of formulations that have to be administered via nebulizer because that's the only way you're going to administer the drug.

*Newhouse: Of course, which is why I presaged my remarks by saying that for reversible airflow obstruction, the best approach is to use a VHC with a pMDI to achieve bronchodilation more quickly and equally effectively as $20 \mathrm{~min}$ with a nebulizer.

MacIntyre: So sayeth the inventor of the AeroChamber!

*Newhouse: Yes, and that's why it was developed.

†Hess: I think there's also something to be said for patients who use multiple classes of drugs to be able to use the same device for all of the drugs they take. The other thing is that the HFA preparations of the pMDIs are very expensive. I don't think we can ignore the cost. When there were generic bronchodilators that were available with CFC pMDIs, the cost was much less than it is now. It's a big cost to hospital pharmacies, which is where my experience is, but it's also a big out-of-pocket expense for patients to use the HFA formulations of the pMDIs.

Rubin: One additional thing to add is that there are impressive changes and developments in nebulizer technology. What was true at the time of inventing the AeroChamber may be changing as we're seeing quieter, faster, easier to use and more efficient nebulizers.

*Newhouse: But they're extremely expensive, if you're talking about vibrating mesh. 
Wise: I think that the bottom line is you have to give the right device to the right patient. There are some patients who just can't use a pMDI properly and those patients do well with nebulizer therapy. The issue of cost, and it's a complicated one that is probably outside the range of this discussion. In the U.S. the cost of nebulized medications is borne by the DME companies and not by the patient, whereas pharmacy costs may be borne by the patient. That is another issue and I'll leave it at that. I don't think one size fits all.

$\dagger$ Hess: About 10 years ago I was part of a writing group for some guidelines $^{5}$ on selection of an aerosol delivery device, and one of the things that we emphasized in that document was the importance of choosing a device that the patient will use. It's not a one size fits all, you need to match the device to the drug to the patient and to the caregiver.

Wise: The other issue in the economics of it. As was mentioned earlier, some hospitals are using all nebulizer therapy simply because it reduces pharmacy costs so much from using a single pMDI per individual. It may increase respiratory therapy costs, but they're not the ones who control the formulary. So some hospitals are moving to just neb therapy - totally on a cost basis. It may lead to a problem if patients are discharged without having an opportunity to demonstrate that they are stable and have the ability to use their home hand-held inhaler treatments.

*Newhouse: That's unique to the U.S. and it derives from a strange advisory that came from the FDA and had to do with the perfectly reasonable request that you not put the boot of the pMDI into people's mouths and go from one to the other. However, you don't need to do that and at the University of Florida they have an advisory at their hospital and they have switched over to pMDI where they can use the pMDI repeatedly on patients. What they do is they clean the boot off between patients, but if they use a holding chamber then the patient does not encounter the end of the pMDI.

Wise: Yeah, and I think someone mentioned that most hospitals in the U.S. prohibit common canister for giving pMDIs on the floors with respiratory therapy. However, virtually every PFT lab is using the same pMDI for every patient who comes in, often with a single-use valved holding chamber.

George: Back to the point of choosing the device that works for the patient and that the patient prefers, really speaks to the need to really use things like the In-Check Dial as a way of assessing what the patient can use and what device might be something that they prefer. Another comment is although we know inhaler technique is poor across populations and across devices, and we aren't doing a whole lot to support and reinforce correct technique at every point of contact. As someone who goes into homes on a regular basis and sees what happens in the setting of using a neb in the home, I think those are patients who are really left with a device without any support or any good information about the care and use of the device. That makes nebulizers particularly challenging in the community setting compared to some of the other devices.

†Hess: I am thinking about the PFT lab vs the acute care setting, and I'm not sure it's a completely fair comparison because many of the patients in the acute care setting are in precautions rooms - contact precautions and so forth. Just as we would not take any other piece of equipment out of that room to another patient, we probably should not do that with a pMDI either.
Strange: Roy [Pleasants] I was impressed with your humidity data ${ }^{6}$ that I had not seen before, and I think this is not common knowledge for those of us who practice in the Southeast. It goes to the heart of whether you leave your inhaler at home or carry it with you.

*Newhouse: The humidity situation is even worse than that. Some years ago we did studies (unpublished data) that showed that within $5 \mathrm{~s}$ of exposure to $75 \%$ humidity the powder in a Turbuhaler became absolutely useless and never recovered. The small particle fraction became about $1 / 4$ of what it had been. And while the total dose remained the same if you sucked very hard, hardly any of it was capable of getting deep into the lower respiratory tract. And that only took $5 \mathrm{~s}$. We did another study where we had people in Canada, and as you know it can be cool there in the winter, put their DPI in their outer pocket and when they walked into the hospital where their glasses would fog up so did the device. Again, it became virtually useless.

Pleasants: It's a big problem for some inhalers that needs to be dealt with and part of it is knowing the problem. So, now you know.

Branson: I'm strictly a critical care practitioner, so we always used updraft nebs and then several of the people in this room presented data showing that pMDIs were just as effective, faster and less expensive. But now the HFAs for some of these drugs make it so much more expensive it's probably cost effective to switch to a mesh nebulizer. My question has always been what Neil was saying, do you need a mesh nebulizer to deliver the dose or can you just let the jet nebulizer run longer? Does anybody want to comment? I get people asking me that all the time. 


\section{Aerosol Delivery Devices for Obstructive Lung Diseases}

$\dagger$ Hess: There are other issues with the use of jet nebulizer and a ventilator circuit. It adds additional flow in the circuit, makes it more difficult to trigger the ventilator, and adds to the tidal volume that is delivered. I would not advocate the use of a jet nebulizer in a ventilator circuit for these reasons that do not related to aerosol delivery per se.

Branson: Even if you ran it from a ventilator that compensates for all that? If you ran it from the ventilator's neb port that only fires during the first two-thirds of inspiration and doesn't add to the volume.

$\dagger$ Hess: Very few manufacturers have nebulizer ports built into the ventilator any more. Maybe you know, Neil, but there aren't very many.

MacIntyre: Some still do. I agree with Michael here, on a ventilator the
pMDI with the proper spacing in the system is really an excellent way of doing it because you control the ventilatory pattern the way it should be. Something I'm afraid patients who are not on ventilators have a lot more difficulty doing.

$\dagger$ Hess: I have no argument with that, but there are still hospital pharmacies that get concerned about the high cost of the HFA formulations. When you do the cost analysis of comparing them - you can use a mesh nebulizer, which has some of the advantages of a pMDI; it adds no flow into the circuit, the device itself stays in the circuit so you do not break the circuit to put it in and so forth - the additional cost of the mesh nebulizer makes it competitive with the cost of an HFA pMDI.

\section{REFERENCES}

1. Consensus Conference V: Aerosols and Delivery Devices. Respir Care 2000;45(6):588-768.
2. Metered Dose Inhalers and Dry Powder Inhalers in Aerosol Therapy. Part 1. Respir Care 2005;50(9):1138-1252.

3. Metered Dose Inhalers and Dry Powder Inhalers in Aerosol Therapy. Part II. Respir Care 2005;50(10):1304-1383.

4. Aerosol Drug Delivery in Respiratory Care. Respir Care 2014;59(6):810-1021.

5. Dolovich MB, Ahrens RC, Hess DR, Anderson P, Dhand R, Rau JL, et al. Device selection and outcomes of aerosol therapy: evidence-based guidelines: American College of Chest Physicians/American College of Asthma, Allergy, and Immunology. Chest 2005;127(1):335-371.

6. Borgström L, Asking L, Lipniunas P. An in vivo and in vitro comparison of two powder inhalers following storage at hot/ humid conditions. J Aerosol Med 2005; 18(3):304-310.

* Michael T Newhouse MD, invited discussant. Dr Newhouse is the chief medical officer for InspiRx.

$\dagger$ Dean R Hess PhD RRT FAARC, discussant. Dr Hess is Managing Editor of ResPIRATORY CARE. 